\title{
IONIC EQUILIBRIA IN DONOR SOLVENTS
}

\author{
U. MAYER \\ Technical University of Vienna, Department of Inorganic Chemistry, \\ A-1060 Vienna, Austria
}

\begin{abstract}
It is shown that coordination chemical and extrathermodynamic models may be successfully applied to the qualitative and also quantitative description of fundamental chemical equilibria and reaction rates in non-aqueous solvents. Applications include: formation of charge transfer complexes, electrochemical reduction of metal cations, ionization of covalent compounds, ion association phenomena, outer sphere interactions and the kinetics of substitution reactions.
\end{abstract}

\section{INTRODUCTION}

During recent decades rapid developments have taken place in the field of non-aqueous solution chemistry. This may be attributed to: first, the increased use of non-aqueous solvents as reaction media in preparative chemistry and in technological processes; and second, the ever-increasing importance of these solvents within the scope of physical chemical studies on the nature of solute-solvent interactions. The previous lack of efficient models for a generalized description of solute-solvent interactions was undoubtedly due to the fact that physical chemists concentrated their efforts for many years on aqueous solutions or at best on a few closely related solvent systems. Thus, only when scientists began to study suitable model reactions in a variety of non-aqueous media with widely different properties has it become possible to establish generalized relationships between chemical reactivity and solvent properties, to test critically existing theories, and to develop new and more efficient models.

The main problem in solution chemistry is the characterization of ionsolvent interactions. It is well known that single ion solvation quantities cannot be determined by purely thermodynamic methods. Consequently, numerous attempts have been made to calculate these quantities by means of electrostatic models. Owing to the systematic investigation of chemical equilibria and chemical kinetics in various non-aqueous solvents, it is now recognized that these models alone are usually inadequate. Ion-solvent interactions may involve considerable contributions from covalent bonding, which cannot be accounted for by purely electrostatic models. The use of structural electrostatic models, in particular, requires a number of parameters such as solvation numbers, ion-molecule distances, and charge distribution within the solvent molecules, which are usually not known with sufficient accuracy or are frequently not known at all. 


\section{U. MAYER}

A basic difficulty associated with the use of even very elaborate electrostatic models arises from the fact that solvation energies of ions are numerically large, whereas differences in solvation energies of a given ion in different solvents are comparatively small. Consequently, small errors in the parameters used may introduce very large errors in the calculation of solvation energy differences. Unfortunately, it is just these small differences in solvation energies which are responsible for the characteristic individual behaviour of the solvents. It is therefore apparent that there is a strong need for new, more efficient models.

In recent years research activities have concentrated in two main areas. First, the evaluation of single ion solvation quantities by means of extrathermodynamic methods; and second, the characterization of ion-solvent interactions by use of coordination chemical models.

Extrathermodynamic methods are based on structural considerations, which make it possible to separate thermodynamic data of electrolytes, obtained by classical methods, into their ionic components. Strehlow in 1960 proposed that the redox potentials of structurally related redox couples such as ferrocene-ferricinium ion, should be essentially independent of the solvent ${ }^{1}$. Such models have been successfully used in electrochemical studies $^{2}$. Other methods rest on the assumption that enthalpy or free energy changes associated with the transfer of a solute from one solvent to another will be nearly equal for structurally analogous ions or molecules. Examples include pairs of structural analogues such as $\left[\mathrm{As}\left(\mathrm{C}_{6} \mathrm{H}_{5}\right)_{4}\right]^{+}-\left[\mathrm{B}\left(\mathrm{C}_{6} \mathrm{H}_{5}\right)_{4}\right]^{-}$, $\left[\mathrm{As}\left(\mathrm{C}_{6} \mathrm{H}_{5}\right)_{4}\right]^{+}-\mathrm{Sn}\left(\mathrm{C}_{6} \mathrm{H}_{5}\right)_{4}$ or (less ideal) $\mathrm{I}_{2}-\mathrm{I}_{3}^{-3,4}$. Very recently free energies of solvation have been evaluated by use of certain types of galvanic cells with negligible liquid-liquid junction potentials ${ }^{5}$. The importance of the extrathermodynamic approach will be treated in detail in the discussion of anion solvation.

The coordination chemical approach to chemical interactions is based on the idea that most chemical reactions, including solute-solvent as well as solute-solute interactions, can be considered as acid-base reactions involving the formation of more or less covalent bonds between the reacting species ${ }^{6,7}$. According to this concept, it should be possible, at least in a qualitative way, to establish general relationships between chemical reactivity and solvent properties, provided that suitable quantities can be defined, which represent a measure of the coordinating properties of the solvents.

This article deals with the application of the coordination chemical approach and the extrathermodynamic approach to fundamental chemical equilibria and the kinetics of chemical reactions in donor solvents. A number of important solvents such as water or the alcohols exhibit well-developed donor and acceptor properties and will also be treated in appropriate places.

\section{SOLVATING POWER OF DONOR SOLVENTS TOWARDS LEWIS ACIDS}

The most characteristic property of donor solvents is the preferential interaction with Lewis acids in the broadest sense of this term.

In an attempt to find a measure of the donor properties of base molecules, Lindqvist determined heats of adduct formation of various donor molecules 


\section{IONIC EQUILIBRIA IN DONOR SOLVENTS}

with antimony pentachloride as reference acceptor in the solvent 1,2dichloroethane ${ }^{8}$. The wide applicability of this approach was realized by Gutmann, who further developed this concept and later introduced the term donor number or donicity for the negative $\Delta H$ value of adduct formation $^{9,10}$. Donor numbers are now available for a large number of inorganic and organic solvents and are listed in Table 1 together with the dielectric constants.

Table 1. Donicities $(D N)$ and dielectric constants $(\varepsilon)$ for several solvents

\begin{tabular}{lrrlrrr}
\hline Solvent & $D N$ & $\varepsilon$ & Solvent & $D N$ & $\varepsilon$ \\
\hline 1,2-Dichloroethane & - & 10.1 & Ethylene carbonate & 16.4 & 89.1 \\
Sulphuryl chloride & 0.1 & 10.0 & Phenylphosphonic difluoride & 16.4 & 27.9 \\
Benzene & 0.1 & 2.3 & Methylacetate & 16.5 & 6.7 \\
Thionyl chloride & 0.4 & 9.2 & n-Butyronitrile & 16.6 & 20.3 \\
Acetyl chloride & 0.7 & 15.8 & Acetone (AC) & 17.0 & 20.7 \\
Tetrachloroethylene carbonate & 0.8 & 9.2 & Ethyl acetate & 17.1 & 6.0 \\
Benzoyl fluoride & 2.0 & 22.7 & Water & 18.0 & 81.0 \\
Benzoyl chloride & 2.3 & 23.0 & Phenylphosphonic dichloride & 18.5 & 26.0 \\
Nitromethane (NM) & 2.7 & 35.9 & Methanol & 19.0 & 32.6 \\
Dichloroethylene carbonate & 3.2 & 31.6 & Diethyl ether & 19.2 & 4.3 \\
Nitrobenzene (NB) & 4.4 & 34.8 & Tetrahydrofuran (THF) & 20.0 & 7.6 \\
Acetic anhydride & 10.5 & 20.7 & Diphenylphosphonic chloride & 22.4 & - \\
Phosphorus oxychloride & 11.7 & 14.0 & Trimethyl phosphate (TMP) & 23.0 & 20.6 \\
Benzonitrile (BN) & 11.9 & 25.2 & Tributyl phosphate (TBP) & 23.7 & 6.8 \\
Selenium oxychloride & 12.2 & 46.0 & Dimethylformamide (DMF) & 26.6 & 36.1 \\
Acetonitrile (AN) & 14.1 & 38.0 & N-methyl- $\varepsilon$-caprolactam & 27.1 & - \\
Sulpholane & 14.8 & 42.0 & $N$-methyl-2-pyrrolidone & 27.3 & - \\
Propanediol-1,2-carbonate & & & N,N-Dimethylacetamide (DMA) & 27.8 & 38.9 \\
(PDC) & 15.1 & 69.0 & Dimethyl sulphoxide (DMSO) & 29.8 & 45.0 \\
Benzyl cyanide & 15.1 & 18.4 & $N, N$-Diethylformamide & 30.9 & - \\
Ethylene sulphite & 15.3 & 41.0 & $N, N$-Diethylacetamide & 32.2 & - \\
iButyronitrile & 15.4 & 20.4 & Pyridine (py) & 33.1 & 12.3 \\
Propionitrile & 16.1 & 27.7 & Hexamethylphosphoric amide & & \\
& & & (HMPA) & 38.8 & 30.0 \\
\hline & & & & &
\end{tabular}

Owing to the fact that 1,2-dichloroethane is a very weakly coordinating solvent, donicity values represent a measure of relative base strength (EPD strength), which is essentially independent of specific solvation effects, in contrast to $\mathrm{p} K_{\mathrm{b}}$ values, which are usually determined in water*. The use of donicity values is based on the idea that coordination chemical reactions can be considered as substitution reactions in which solvent molecules are replaced by competitive ligands, and that the relative order of donor strengths observed towards antimony pentachloride is essentially independent of the nature of the acceptor groups. The latter assumption has indeed been confirmed for both neutral and cationic acids ${ }^{6,10}$. An example is provided by the interaction of iodine with base molecules. In Figure 1 heats of adduct

* The following abbreviations will be used throughout this article: EPD = electron pair donor, EPA = electron pair acceptor. 


\section{U. MAYER}

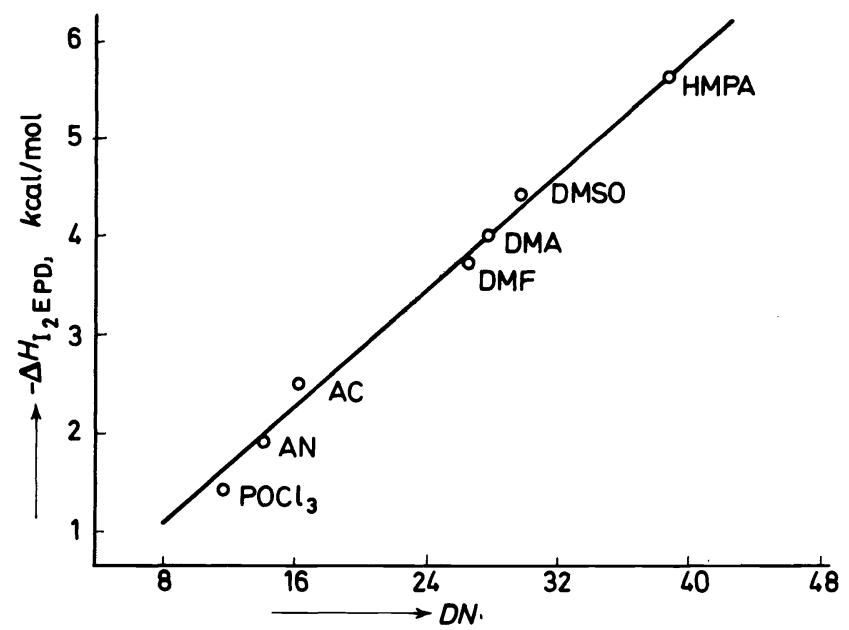

Figure 1. Heats of formation of one to one adducts of iodine with various donors (measured in carbon tetrachloride or hexane) as a function of $D N$

formation of iodine have been plotted versus the donicity of the solvent molecules ${ }^{11}$. A linear correlation is obtained. The slope of the curve of tan $\phi=0.15$ represents a measure of the acceptor strength of iodine relative to $\mathrm{SbCl}_{5}$. Similar plots have been obtained for other acceptor molecules such as phenol, trimethyltin chloride and vanadyl(IV)acetylacetonate. In Figure 2

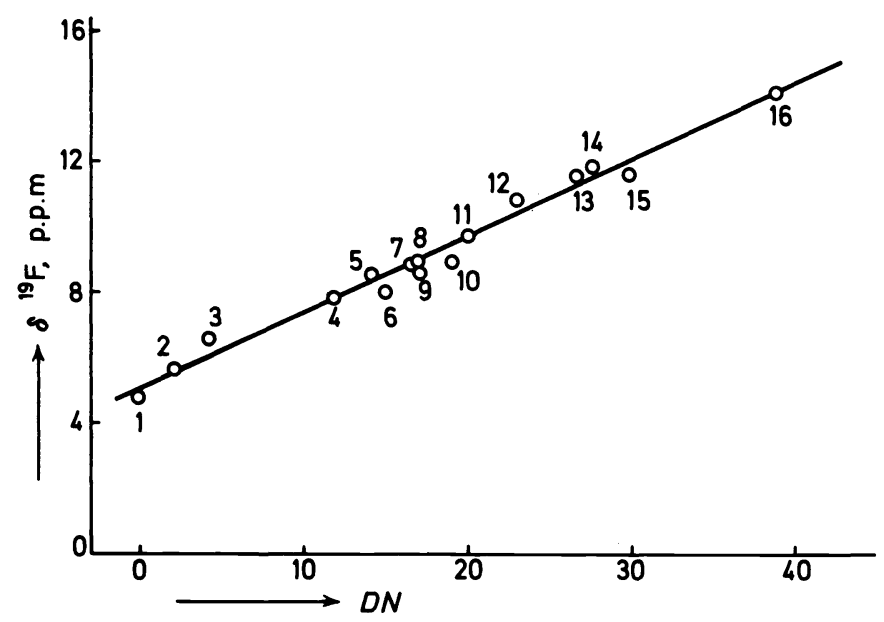

Figure $2 .{ }^{19} \mathrm{~F}$ chemical shifts of trifluoroiodomethane in various donor solvents as a function of $D N$, referred to $\mathrm{CCl}_{3} \mathrm{~F}$ as external reference: 1, 1,2-dichloroethane; 2, benzoyl chloride; 3 , nitrobenzene; 4 , benzonitrile; 5 , acetonitrile; 6 , propanediol-1,2-carbonate; 7 , methylacetate; 8 , acetone; 9 , ethylacetate; 10 , diethylether; 11 , tetrahydrofuran; 12 , trimethyl phosphate; 13 , dimethylformamide; $14, N, N$-dimethylacetamide; 15 , dimethyl sulphoxide; 16 , hexamethylphosphoric amide 
${ }^{19} \mathrm{~F}$ chemical shifts of trifluoroiodomethane dissolved in various donor solvents have been plotted against the donicity ${ }^{12}$. Again a linear correlation is observed. Nucleophilic attack of the donor molecule at the iodine atom increases the electron density at the fluorine atoms and shifts the signal to higher field:

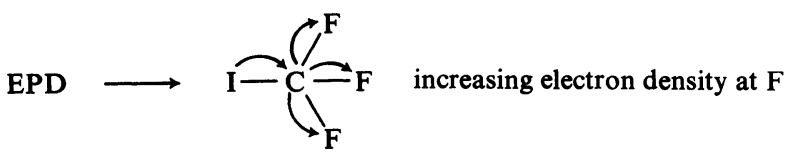

The magnitude of the shift increases with increasing donicity of the solvent. This correlation allows a rapid and simple estimation of the base strength of solvent molecules.

The results which have been observed in the interaction of iodine and trifluoroiodomethane with solvent molecules are interesting also from the theoretical point of view in that they show that the coordination chemical approach can be successfully applied even to weak molecular interactions ${ }^{44,56}$. In contrast, the observed relationships cannot be accounted for either in terms of Mulliken's theory of charge transfer interactions or on the basis of elementary electrostatic models.

The application of the donicity concept to cation solvent interactions has been demonstrated by polarographic measurements on various metal ions in a large number of non-aqueous solvents ${ }^{13,14}$. Figure 3 shows the basic

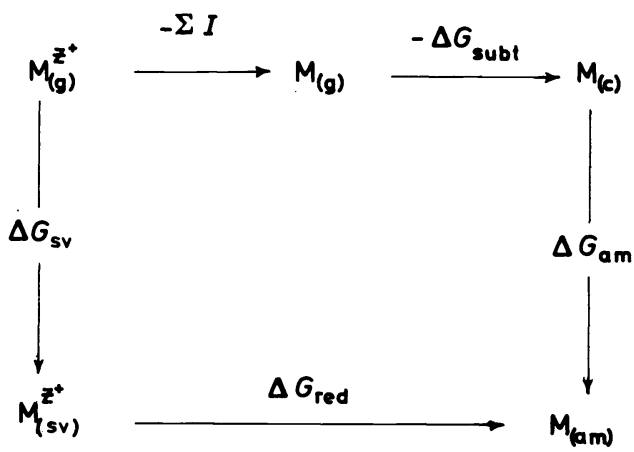

Figure 3. Thermochemical cycle for the polarographic reduction of a metal cation to the metal amalgam

relationship between redox potential and solvation energy for the reduction of a metal cation at the dropping mercury electrode:

$$
\begin{gathered}
\Delta G_{\mathrm{red}}=-\Delta G_{\mathrm{sv}}-\Sigma I-\Delta G_{\mathrm{subl}}+\Delta G_{\mathrm{am}} \\
\Delta G_{\mathrm{red}} \approx-Z F E_{1 / 2} \text { (for reversible reductions) }
\end{gathered}
$$




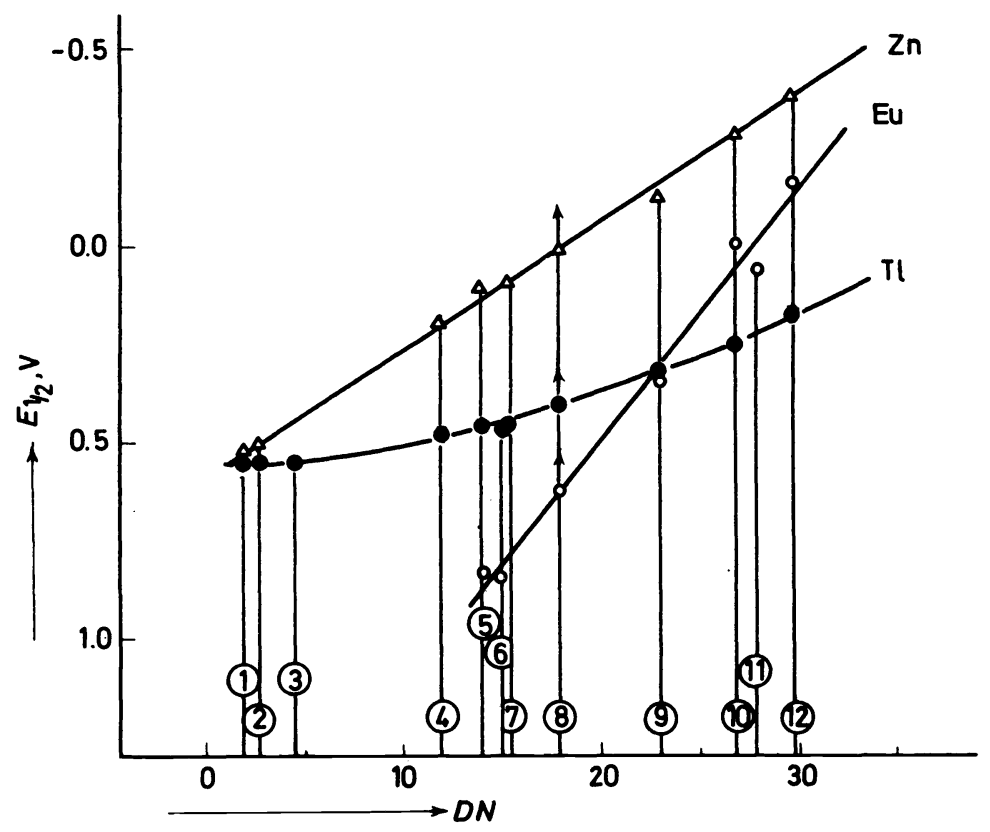

Figure 4. Half-wave potentials for the polarographic reduction of $\mathrm{Tl}^{+}$to $\mathrm{Tl}^{0}, \mathrm{Zn}^{2+}$ to $\mathrm{Zn}^{0}$ and $\mathrm{Eu}^{3+}$ to $\mathrm{Eu}^{2+}$ referred to bisdiphenylchromium(I) iodide in various donor solvents as a function of $D N$ : 1 , benzoyl fluoride; 2 , nitromethane; 3 , nitrobenzene; 4 , benzonitrile; 5 , acetonitrile; 6, propanediol-1,2-carbonate; 7 , ethylene sulphite; 8 , water; 9 , trimethyl phosphate; 10 , dimethylformamide; 11, dimethylacetamide; 12 , dimethylsulphoxide

According to equations (1) and (2) the half-wave potential for the reversible reduction of a given ion is merely a function of the free energy of solvation. Experimental results for the reversible reductions of $\mathrm{Tl}^{+}$to $\mathrm{Tl}^{0}, \mathrm{Zn}^{2+}$ to $\mathrm{Zn}^{0}$ and $\mathrm{Eu}^{3+}$ to $\mathrm{Eu}^{2+}$ are represented in Figure 4. With increasing donicity, half-wave potentials are generally shifted to more negative potential values. This means that the cations are increasingly stabilized with increasing donor strength of the solvents. Negative shifts observed in the reduction of $\mathrm{Eu}^{3+}$ to $\mathrm{Eu}^{2+}$ are due to the fact that $\mathrm{Eu}^{3+}$ is a much stronger acceptor than $\mathrm{Eu}^{2+}$. Consequently, $\mathrm{Eu}^{3+}$ is increasingly stabilized as compared with $\mathrm{Eu}^{2+}$, with increasing donicity of the solvent.

Comparison of the reduction curves for $\mathrm{Tl}^{+}$and $\mathrm{Eu}^{3+}$ suggests that the ordering of redox couples within the electromotive series may depend on the donor strength of the solvent. Half-wave potentials for the reduction of $\mathrm{Eu}^{3+}$ decrease more rapidly than those for $\mathrm{Tl}^{+}$. This corresponds to an increase in reducing power of $\mathrm{Eu}^{2+}$ as compared with $\mathrm{Tl}^{\circ}$, with increasing donicity of the solvent. Calculation of standard redox potentials from halfwave potentials of course requires the knowledge of the free energies of amalgamation.

In order to eliminate the variable influence of liquid-liquid junction potentials, half-wave potentials in Figure 4 have been referred to bisdiphenylchromium(1)iodide. Since this compound is unstable in water (the same 


\section{IONIC EQUILIBRIA IN DONOR SOLVENTS}

applies to the ferricinium ion), it is difficult to obtain reliable half-wave potentials. Estimates, however, clearly reveal that half-wave potentials in water are more negative than would be expected according to its donicity $(D N=18)^{2,14}$. The following explanation has been offered to account for this behaviour ${ }^{14}$. Desolvation of a metal cation on reduction leads to an increase in entropy. Since water is a highly structured liquid, the increase in entropy will be considerably smaller than in aprotic solvents. Consequently, the half-wave potential is shifted to more negative values. In addition, a second effect is operative. Coordination of water molecules to strong EPA units leads to an increase in the acidity of the hydrogen atoms. Outer-sphere interactions between the acidic hydrogen atoms and additional water molecules lead to an increase in electron density at the oxygen atoms immediately coordinated to the metal ion:

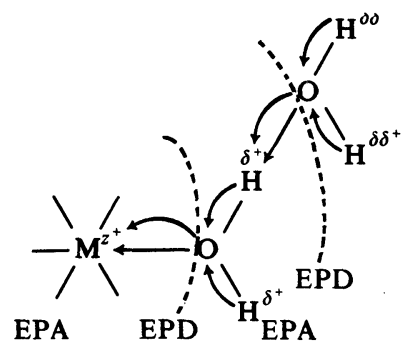

As a consequence, the effective donor strength of the solvent molecules is enhanced as compared with that of the unassociated molecules ${ }^{14}$. Obviously both effects are interrelated and are generally characteristic of solvents with well-developed amphoteric properties.

It should be mentioned that in Figure 4 an enthalpy quantity $(D N)$ has been related to a free energy quantity. Such a correlation can be expected only if either variations in the entropies of solvation are small or the entropy is approximately linearly dependent on the enthalpy term.

Finally, it should be mentioned that in a number of cases exceptions have been observed from the donicity rule. Coetzee, for example, has shown that nitrile solvents exhibit an unusually high affinity towards $\mathrm{Ag}^{+}$and particularly $\mathrm{Cu}^{+15,16}$. It appears that nitriles may act both as $\sigma$ donors and $\pi$ acceptors towards metal cations with highly filled $d$ orbitals. Likewise, thioamides behave as extremely strong donors towards $\mathrm{Ag}^{+}$(DN extrapolated $\approx 45)$ but as very weak donors towards alkali metal ions $(D N \approx$ $8-10)^{17}$. In practice, these exceptions do not seriously restrict the applicability of the donicity concept, since most solvents and substrates show either hard or borderline behaviour.

\section{SOLVATING POWER OF DONOR SOLVENTS TOWARDS ANIONS}

In the majority of chemical reactions both cations and anions are involved. The course of these reactions, therefore, depends not only on the EPD properties of the solvents but also on their solvating power towards anions. 


\section{U. MAYER}

Unfortunately, it has not yet been possible to define suitable empirical quantities which could be used as a measure of the solvating properties of donor solvents towards anions.

Data which represent a measure of the anion solvating power of donor solvents have been determined by means of extrathermodynamic assumptions. Table 2 lists values for the free energies of solvation of $\mathrm{Cl}^{-}$for various solvents referred to the solvent acetonitrile ${ }^{18}$. The values have been calculated from solvent activity coefficient data available in the literature ${ }^{5}$. The

Table 2. Free energies of solvation of $\mathrm{Cl}^{-}$for various solvents $\mathrm{S}$ referred to the solvent acetonitrile

\begin{tabular}{lclc}
\hline Solvent & $\Delta G_{\mathrm{sv}}^{\mathrm{S}}\left(\mathrm{Cl}^{-}\right)-\Delta G_{\mathrm{sv}}^{\mathrm{AN}}\left(\mathrm{Cl}^{-}\right)$ & Solvent & $\Delta G_{\mathrm{sv}}^{\mathrm{S}}\left(\mathrm{Cl}^{-}\right)-\Delta G_{\mathrm{sv}}^{\mathrm{AN}}\left(\mathrm{Cl}^{-}\right)$ \\
\hline Water & -8.71 & DMSO & 0.00 \\
Methanol & -5.98 & TMS & 0.14 \\
Ethanol & -4.76 & DMF & 1.22 \\
NM & -3.13 & DMA & 2.45 \\
PDC & -0.14 & Acetone & 3.45 \\
AN & 0.00 & HMPA & 4.08 \\
\hline
\end{tabular}

results show that donor solvents may differ considerably in their solvating power towards anions. Hence, chemical equilibria and reaction rates not only will depend on the donor properties of the solvents but may also be strongly influenced by differences in the anion solvating power ${ }^{18,19}$. The solvating properties decrease in the series:

\section{Water $\gg$ methanol $>$ ethanol $>\mathrm{NM} \gg \mathrm{PDC} \geqslant \mathrm{AN}=\mathrm{DMSO} \geqslant \mathrm{TMS}>$ DMF $>$ DMA $>$ acetone $>$ HMPA}

The strong solvating properties of water and the lower alcohols are due to the formation of hydrogen bonds. On the other hand, anions are only poorly solvated in acetone, DMA and HMPA. The weak anion solvating power of HMPA arises from the fact that the positive centre of the dipole molecule is completely surrounded by donor atoms. The solvating properties of PDC, AN, DMSO and TMS are hardly differentiated. Nitromethane is a good solvating solvent for anions owing to the electron-attracting power of the nitro group.

Comparison of Tables 1 and 2 reveals that, contrary to what would be expected from macroscopic electrostatic models, there is no relationship between the free energies of solvation and the dielectric constants of the solvents.

\section{IONIZATION OF COVALENT COMPOUNDS. THE ROLE OF THE DIELECTRIC CONSTANT}

Ionization of covalent substrates is a fundamental process in solution. In the earlier literature it is frequently stated that this process is primarily dependent on the dielectric properties of the medium. In fact, it is predicted 
from macroscopic electrostatic models that ions are increasingly stabilized with increasing dielectric constant of the solvent ${ }^{20,21}$.

Systematic investigations on the ionization of covalent compounds have clearly revealed that differences in the degree of ionization of a given substrate are primarily determined by the coordinating properties of the solvents ${ }^{2-24}$. This is due to the fact (see Section VIII) that free energy changes associated with the dielectric polarization of the solvent molecules in the field of the ions are numerically large, but rather unspecific as compared with the energy changes associated with specific ion solvent interactions in the inner solvation sphere. These specific interactions cannot usually be rationalized by electrostatic theories; however, they can frequently be described on the basis of the coordination chemical model.

In general, ionization of a covalent compound proceeds in two steps $^{13,18,22}$ :

$$
\begin{array}{r}
\mathrm{X}-\mathrm{Y}+\mathrm{nEPD} \stackrel{K_{\mathrm{i}}}{\rightleftharpoons}\left[\left(\mathrm{X} \cdot \mathrm{EPD}_{n}\right)^{+} \mathrm{Y}^{-}\right]^{0} \stackrel{K_{\mathrm{d}}}{\rightleftharpoons}\left(\mathrm{X} \cdot \mathrm{EPD}_{n}\right)^{+}+\mathrm{Y}^{-} \\
\mathrm{X}-\mathrm{Y}+\mathrm{mEPA} \rightleftharpoons\left[\mathrm{X}^{+}\left(\mathrm{Y} \cdot \mathrm{EPA}_{m}\right)^{-}\right]^{0} \rightleftharpoons \mathrm{X}^{+}+\left(\mathrm{Y} \cdot \mathrm{EPA}_{m}\right)^{-} \\
\mathrm{X}-\mathrm{Y}+\mathrm{nEPD}+\mathrm{mEPA} \rightleftharpoons\left[\left(\mathrm{X} \cdot \mathrm{EPD}_{n}\right)^{+}\left(\mathrm{Y} \cdot \mathrm{EPA}_{m}\right)^{-}\right]^{0} \rightleftharpoons\left(\mathrm{X} \mathrm{EPD}_{n}\right)^{+} \\
+\left(\mathrm{Y} \cdot \mathrm{EPA}_{m}\right)^{-}
\end{array}
$$

Equations (3) $-(5)$ refer to donor, acceptor and amphoteric solvents, respectively.

In each case the reaction between the substrate and the solvent molecules leads to the formation of an ion pair, which then undergoes dissociation into free ions. Step 1 is characterized by the ionization constant $K_{\mathrm{i}}$ and is primarily a function of the specific solvating (coordinating) properties of the solvent. Step 2 is characterized by the dissociation constant $K_{\mathrm{d}}$ and is mainly determined by the dielectric properties of the solvent, provided that the constituent ions of the ion pair do not undergo strong specific interactions with the solvent molecules. Otherwise even $K_{\mathrm{d}}$ may be influenced by specific solvation effects, as will be shown in the discussion of ion pair association and outer-sphere equilibria.

Under favourable conditions $K_{\mathrm{i}}$ and $K_{\mathrm{d}}$ may be determined separately by use of different experimental techniques. In solvents with high dielectric constants (e.g. in water) ion pairs are usually unstable and the substrate is directly converted into free ions. In this case $K_{\mathrm{i}}$ and $K_{\mathrm{d}}$ cannot be determined separately and the ionization process is best characterized by the classical dissociation constant $K_{\text {class, }}$, which, by definition, equals the product of $K_{\mathrm{i}}$ and $K_{\mathrm{d}}$ :

$$
K_{\text {class }}=\frac{c_{\mathbf{X}^{+}} \times c_{\mathbf{Y}^{-}}}{c_{\mathbf{X}-\mathbf{Y}}}=K_{\mathrm{i}} \times K_{\mathrm{d}}
$$

If, on the other hand, ionization takes place in a strongly coordinating solvent with low dielectric constant (e.g. tributylphosphate), then only solvent separated ion pairs will be formed. In this case the classical dissociation constant is misleading and the ionization process is best characterized by $K_{\mathrm{i}}$. The foregoing considerations show that caution should be observed 
in the use of classical dissociation constants as a measure of acid or base strengths in solvents of different dielectric constants. Small ionization constants' sometimes observed in strong basic media with low dielectric constants (e.g. pyridine) may actually turn out to be dissociation constants owing to the fact that the substrate is fully ionized but that the ions formed are strongly associated.

Under suitable experimental conditions it is possible to study ionization reactions without interference from the variable dielectric properties of the pure solvents. An example is provided by the ionization of trimethyliodostannane. This reaction has been studied conductometrically in nitrobenzene solution by addition of increasing amounts of various donor solvents ${ }^{22}$. Ionization proceeds according to the following scheme:

$\mathrm{Sn}\left(\mathrm{CH}_{3}\right)_{3} \mathrm{I}+2 \mathrm{EPD} \stackrel{K_{\dot{j}}}{\rightleftharpoons}\left[\left(\mathrm{Sn}\left(\mathrm{CH}_{3}\right)_{3} \cdot \mathrm{EPD}_{2}\right)^{+} \mathrm{I}^{-}\right]^{0} \stackrel{K_{d}}{\rightleftharpoons}\left(\mathrm{Sn}\left(\mathrm{CH}_{3}\right)_{3} \cdot \mathrm{EPD}_{2}\right)^{+}+\mathrm{I}^{-}$

Since nitrobenzene is present in excess during the titration, the dielectric constant of the medium remains essentially constant. Hence, the molar conductances represent a direct measurement of the strength of the coordination chemical interaction between the trimethyltin cation and the donor

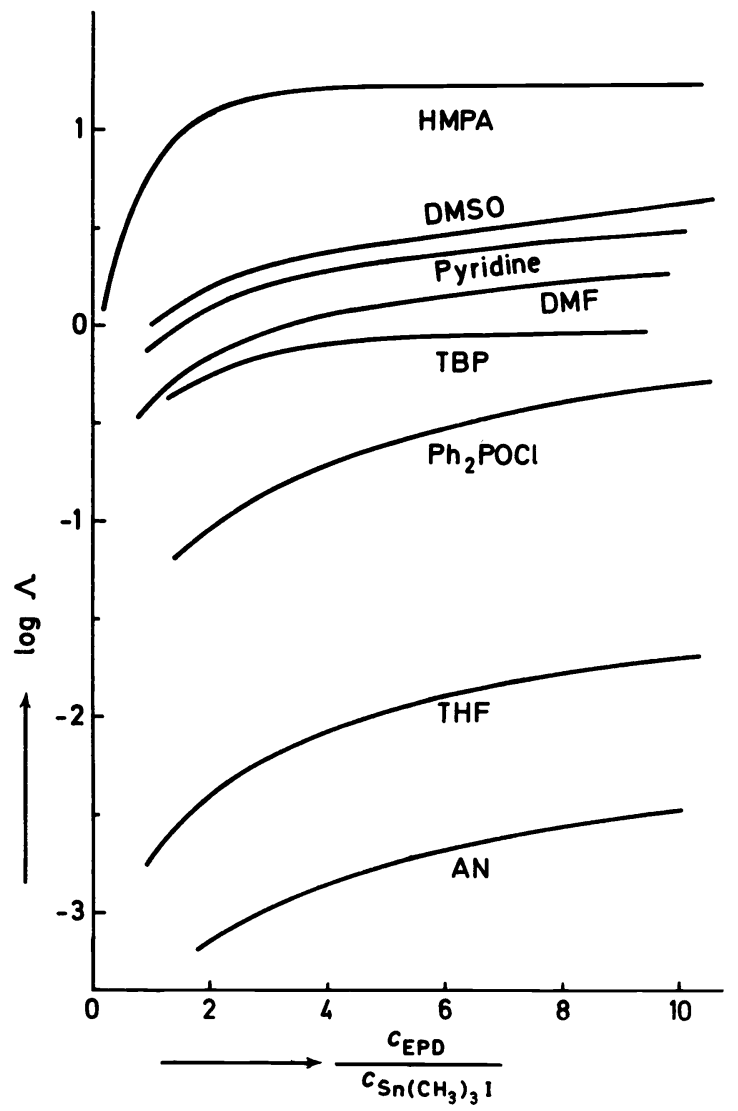

Figure 5. Molar conductivites of trimethyltin iodide $\left(c=7 \times 10^{-2} \mathrm{~mol} / 1\right)$ dissolved in nitrobenzene on addition of increasing amounts of various donor solvents 


\section{IONIC EQUILIBRIA IN DONOR SOLVENTS}

molecules*. In pure nitrobenzene, which is a poor donor, trimethyliodostannane is present un-ionized. Since nitrobenzene has a fairly high dielectric constant $(\varepsilon=34.8)$, this indicates that the dielectric constant alone is not sufficient to effect ionization. Figure 5 reveals that the molar conductances at a given mole ratio of donor to substrate increase with increasing donor strength of the solvent molecules. The only exception is pyridine. A similar observation has been made in studies on Lewis acid-base interactions by Drago $^{25}$. He pointed out that the reduced donor strength of pyridine may be due to a specific interaction of its $\pi$ electron system with the $\pi$ electrons of the nitrobenzene molecules.

Similar results have recently been obtained for trimethylsilicon and trimethylgermanium halides ${ }^{26}$. Again, the extent of ionization increases with increasing donicity. In strong EDP solvents, such as HMPA, DMF or pyridine, $\mathrm{Si}\left(\mathrm{CH}_{3}\right)_{3} \mathrm{I}$ is completely ionized with formation of stable siliconium ions $\left[\mathrm{Si}\left(\mathrm{CH}_{3}\right)_{3} \cdot \mathrm{EPD}_{2}\right]^{+}$and $\mathrm{I}^{-}$. This appears interesting, since at present very little is known about the existence of stable siliconium ions in solution $^{27-29}$.

* The variation of $K_{\mathrm{d}}$ with the radius of the solvated cation is negligible.

\section{ION ASSOCIATION PHENOMENA}

Formation of ion pairs or higher ionic aggregates (triple ions, etc.) is a very common and characteristic phenomenon in non-aqueous media. Two types of ion pairs are usually distinguished, namely 'contact ion pairs' and 'solvent separated ion pairs'.

In many cases there appears to be no basic difference between the electrolytic behaviour of 'contact ion pairs' and the ionization of covalent compounds. Recent x-ray investigations, for example, have shown that covalent bonding must be involved in the interaction between alkali metal ions and various carbanions derived from unsaturated carbohydrates ${ }^{30}$. Such ion pairs may therefore equally well be considered as un-ionized species ${ }^{6,14}$. Results of spectroscopic studies on solutions of lithium and sodium fluorenide in a few solvents are listed in Table 3.

Comparison of the extent of ionization reveals that the electrolytic behaviour primarily depends on the donor properties and not on the dielectric constants or the dipole moments of the solvents. The influence of anion solvation is expected to be small, owing to the high degree of charge dis-

Table 3. Ionization of lithium and sodium fluorenide in various EPD solvents at $25^{\circ} \mathrm{C}^{31,32}$

\begin{tabular}{|c|c|c|c|c|c|}
\hline \multirow[t]{2}{*}{ Solvent } & \multirow[t]{2}{*}{$D N$} & \multirow[t]{2}{*}{$\boldsymbol{\varepsilon}$} & \multirow[t]{2}{*}{$\mu$} & \multicolumn{2}{|c|}{$\begin{array}{c}\text { Per cent ionized substrate } \\
\text { (solvent separated ion pairs }+ \text { free ions) }\end{array}$} \\
\hline & & & & Lithium fluorenide & Sodium fluorenide \\
\hline THF & 20.0 & 7.6 & 1.75 & 75 & 5 \\
\hline DMSO & 29.8 & 45.0 & 3.90 & 100 & 100 \\
\hline Pyridine & 33.1 & 12.3 & 2.30 & 100 & 100 \\
\hline
\end{tabular}




\section{U. MAYER}

persion within the carbanion. Lithium fluorenide is fully ionized in DMSO and also in pyridine, although pyridine has a lower dielectric constant and a smaller dipole moment than DMSO. Both solvents are very strong donors. Since DMSO has a high dielectric constant, ionization in this solvent leads to the formation of free ions. In contrast, separated ion pairs are formed in pyridine, which is a strong base but a weak dissociating medium. Ionization of lithium fluorenide is incomplete in tetrahydrofuran, which is a moderately strong donor. However, the percentage of solvent separated ion pairs formed is much higher than would be expected according to the low dielectric constant and the small dipole moment of this solvent.

Sodium fluorenide is also fully ionized in DMSO and pyridine. In THF the extent of ionization is much smaller than in the case of lithium fluorenide. This is due to the fact that the sodium ion is a much weaker acceptor than the lithium ion. Hence, the influence of the coordinating properties of the solvent is decreased as compared with the influence of purely electrostatic interactions. This should particularly apply to caesium fluorenide, which can presumably be considered as the limiting case of a true contact ion pair. 'Contact ion pairs' have further been detected in solutions of various alkali metal halides in weakly coordinating solvents such as nitromethane, acetone or propanediol-1,2-carbonate (PDC). Recent conductometric measurements have shown that lithium halides are associated in PDC but are fully ionized in hexamethylphosphoric amide (HMPA) ${ }^{33}$. This behaviour is easily understood from the coordination chemical point of view but is inconsistent with elementary electrostatic models. Donor strengths of various anions and solvent molecules have been determined in the solvent acetonitrile with vanadyl(IV) acetylacetonate as reference acceptor ${ }^{34}$. Figure 6 reveals that

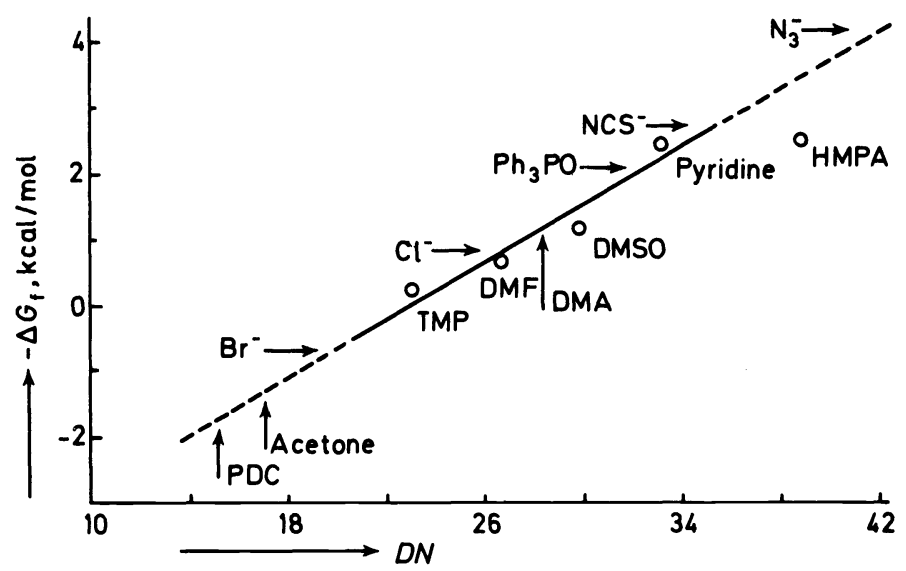

Figure 6. Free energies of formation of one to one adducts of vanadyl(IV) acetylacetonate with various neutral and anionic ligands, measured in the solvent acetonitrile

the $\mathrm{Cl}^{-}$ion is a stronger donor than PDC. Hence, the PDC molecules can be easily replaced by $\mathrm{Cl}^{-}$ion in the solvation shell of the $\mathrm{Li}^{+}$ion with formation of the un-ionized species LiX. On ionization, these species (which 
are of course solvated) are directly converted into free ions, owing to the high dielectric constant of the solvent. The behaviour of lithium halides in PDC is therefore entirely analogous to the behaviour of, for example, acetic acid in water. In contrast, lithium halides are fully ionized in HMPA. HMPA is a stronger donor than the solvated $\mathrm{Cl}^{-}$ion, so that the $\mathrm{Li}^{+}$ion is surrounded by a tight solvation shell. Ion pairs are at the same time fully dissociated, owing to the large effective radius of the solvated cation.

The importance of the coordination chemical approach and the failure of elementary electrostatic models has been further demonstrated in numerous spectroscopic investigations on 'contact ion pair' equilibria. Popov, for example, has shown that $\mathrm{LiClO}_{4}$ is present as contact ion pairs in nitromethane ${ }^{35}$. On addition of acetone, solvent separated ion pairs are formed with four molecules of acetone coordinated to the $\mathrm{Li}^{+}$ion. This is due to the higher donicity of acetone (acetone: $D N=17.0$; nitromethane: $D N=2.7$ ). The reverse behaviour would be expected according to the dipole moments (acetone: $\mu=2.88$ Debye; nitromethane: $\mu=3.57$ Debye).

Similar results have been obtained by Edgell and Popov in solution studies on cage vibrations of alkali metal salts. Band frequencies are nearly independent of the nature of the anion in solvents with high donicities such as DMSO, pyridine or 1-methyl-2-pyrrolidone, but are strongly dependent on the anion in comparatively weak donor solvents such as acetone ${ }^{36-42}$. Electrostatic models may be applied when the ions are either coordinatively saturated or do not undergo strong specific interactions with the solvent molecules ${ }^{18}$. Fuoss and Eigen have derived the following equation, which relates the ion pair association constant to the dielectric constant of the solvent and the centre-to-centre distance $a$ of the ions within the ion pair :

$$
K_{\text {ass }}=\frac{4 \pi a^{3} N}{3000} \exp \left[\frac{z_{1} z_{2} e^{2}}{\varepsilon a k T}\right]
$$

Association constants of tetrabutylammonium iodide are listed in Table $4^{18}$.

Table 4. Ion pair association constants $K_{\text {ass }}$ of tetrabutylammonium iodide in various solvents at $25^{\circ} \mathrm{C}$

\begin{tabular}{lrrlrr}
\hline Solvent & $\varepsilon$ & $K_{\text {ass }}$ & Solvent & $\varepsilon$ & $K_{\text {ass }}$ \\
\hline Pyridine & 12.3 & 2400 & Methanol & 32.6 & 16 \\
1-Butanol & 17.5 & 1200 & DMF & 36.7 & 8 \\
1-Propanol & 20.1 & 415 & AN & 36.0 & 3 \\
Methylethylketone & 18.5 & 380 & DMA & 37.8 & 0 \\
Acetone & 20.7 & 143 & DMSO & 46.7 & 0 \\
Ethanol & 24.3 & 123 & N-Methyl- & & \\
NB & 34.8 & 27 & acetamide & 165.5 & 0 \\
\hline
\end{tabular}

It is realized that the over-all trend roughly corresponds to theory.

With increasing charge density or EPD strength of the anion, specific solvation effects become increasingly important. Tetraalkylammonium chlorides are more extensively dissociated in methanol $(\mu=1.71$ Debye; $\varepsilon=32.6)$ than in acetonitrile $(\mu=3.37$ Debye; $\varepsilon=36.0)$ or nitromethane 


\section{U. MAYER}

( $\mu=3.57$ Debye $; \varepsilon=35.9$ ). This is undoubtedly due to specific solvation of the $\mathrm{Cl}^{-}$ion via hydrogen bonds. Again, this behaviour cannot be rationalized by elementary electrostatic considerations. Both the dielectric constant and the dipole moment are smaller for methanol than for acetonitrile or nitromethane.

\section{OUTER-SPHERE INTERACTIONS}

It has been stated that the enhanced donor properties of water in the pure liquid state, as observed in the polarographic reduction of transition metal ions, are due to outer-sphere interactions between water molecules of the inner and outer hydration shells. This type of interaction is, of course, not restricted to interactions between solvent molecules ${ }^{18,43,44}$. Generally, the term outer-sphere coordination may be applied to all interactions involving formation of coordinate bonds between neutral or charged coordinated ligands and neutral or charged reactants.

Formation of outer sphere complexes was predicted as early as 1912 by Werner to account for the stereochemical course of substitution reactions and was later postulated (and subsequently experimentally confirmed) by kineticists to explain certain features of rate laws observed in reactions of transition metal-ammine complexes ${ }^{45-47}$. The importance of outer-sphere interactions in substitution reactions of various transition metal complexes was recently discussed by Gutmann and Schmid ${ }^{43}$. Examples include the solvolysis of $\left[\mathrm{Cr}\left(\mathrm{NH}_{3}\right)_{4}(\mathrm{NCS})_{2}\right]^{+}$, which proceeds more rapidly in hydroxylic than in aprotic solvents ${ }^{48}$. This observation was ascribed to the labilization of the leaving ligand by hydrogen bond formation ${ }^{43}$. A similar explanation was given for the catalytic action of protons and metal cations in the aquation of $\left[\mathrm{Cr}\left(\mathrm{H}_{2} \mathrm{O}\right)_{5} \mathrm{Cl}\right]^{2+}$ and cis- $\left[\mathrm{Ru}\left(\mathrm{NH}_{3}\right)_{4}\left(\mathrm{H}_{2} \mathrm{O}\right) \mathrm{Cl}\right]^{+49-51}$ :

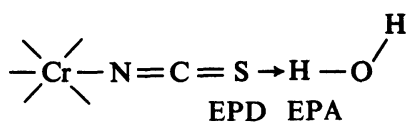

Outer-sphere effects by EPA ligands have recently been studied by means of the polarographic reduction of the hexacyanoferrate(III) ion to the hexacyanoferrate(II) ion in propanediol-1,2-carbonate ${ }^{52}$. Figure 7 shows that half-wave potentials are shifted to more positive values on addition of hydroxylic solvents. This is due to the fact that the nitrogen atoms in the hexacyanoferrate(II) ion are more basic than in the hexacyanoferrate(III) ion. Thus, the reduced species is more strongly stabilized by outer-sphere interaction with EPA molecules than the oxidized species. As expected, shifts increase in the series $\mathrm{H}_{2} \mathrm{O}>\mathrm{CH}_{3} \mathrm{OH}>\mathrm{C}_{2} \mathrm{H}_{5} \mathrm{OH}$ corresponding to the increasing EPA properties of these molecules. Clearly, this behaviour cannot be explained by elementary electrostatic models. In the case of methanol and ethanol the reverse behaviour should be expected, since addition of methanol and ethanol to PDC decreases the dielectric constant of the solvent mixture.

A particularly instructive example of outer-sphere interactions is provided 


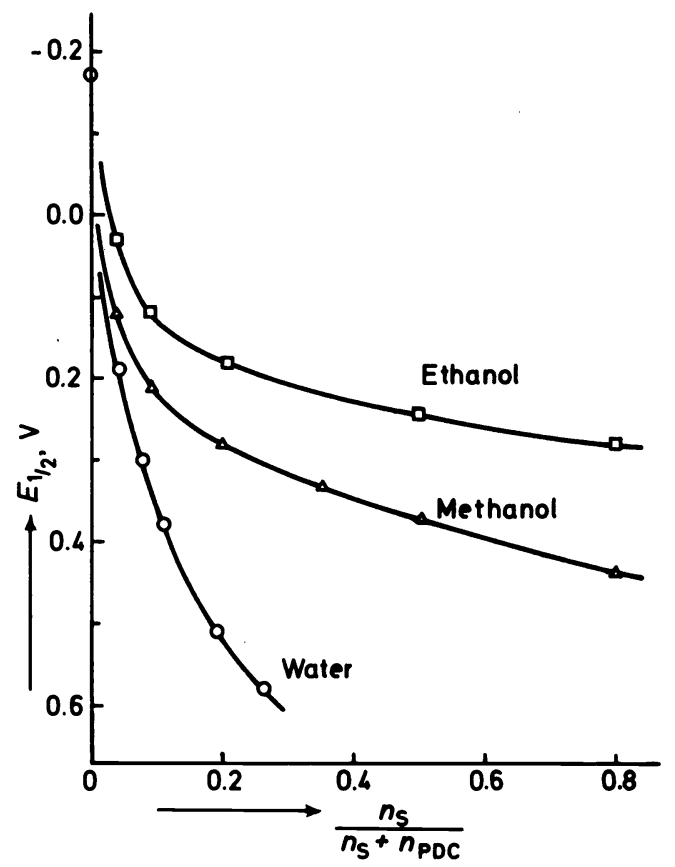

Figure 7. Half-wave potentials for the polarographic reduction of hexacyanoferrate(III) to hexacyanoferrate(II) in the solvent propanediol-1,2-carbonate on addition of increasing amounts of hydroxylic solvents (reference depolarizer $=$ bisdiphenylchromium(I)iodide).

by the interaction between cis- $\left[\mathrm{Co}(\mathrm{en})_{2} \mathrm{Cl}_{2}\right]^{+}$and various anions. Formation constants for the outer-sphere interaction between cis-[Co(en $\left.)_{2} \mathrm{Cl}_{2}\right]^{+}$and $\mathrm{Cl}^{-}$have been determined in various solvents and are listed in Table $5{ }^{53,54}$.

Table 5. Formation constants for the one-to-one outer-sphere complex between $\left[\mathrm{Co}(\mathrm{en})_{2} \mathrm{Cl}_{2}\right]^{+}$and $\mathrm{Cl}^{-}$in various solvents at $25^{\circ} \mathrm{C}$

\begin{tabular}{lccccc}
\hline Solvent & $K_{\text {out }}$ & $D N$ & $\Delta G_{\mathrm{sv}}^{\mathrm{s}}\left(\mathrm{Cl}^{-}\right)-\Delta G_{\mathrm{sv}}^{\mathrm{M}}\left(\mathrm{Cl}^{-}\right)$ & $\varepsilon$ & $\mu$ \\
\hline Methanol (M) & 150 & 19.0 & 0.00 & 32.6 & 1.71 \\
DMSO & 400 & 29.8 & 5.98 & 46.7 & 3.90 \\
DMF & 8000 & 26.6 & 7.20 & 36.7 & 3.86 \\
DMA & 20000 & 27.8 & 8.43 & 37.8 & 3.81 \\
TMS & $42000^{*}$ & 14.8 & 6.12 & 42.0 & 4.81 \\
\hline
\end{tabular}

It is realized that the formation constants are surprisingly large-in fact, much higher than would be expected according to electrostatic models. This may be taken as strong evidence for coordination chemical interactions between the chloride ion and the acidic hydrogen atoms of the coordinated ethylenediamine molecules. Recent polarographic measurements carried out in this laboratory have unambiguously proved the acidic nature of hydrogen atoms bonded to nitrogen in transition metal-ammine complexes ${ }^{55}$. 


\section{U. MAYER}

Half-wave potentials for the reversible reduction of $\left[\mathrm{Co}(\mathrm{en})_{3}\right]^{3+}$ (supplied as the perchlorate salt) to $\left[\mathrm{Co}(\mathrm{en})_{3}\right]^{2+}$ depend on the EPD properties of the solvent molecules and are shifted to more negative potential values with increasing solvent donicity. Increasing positive charge of the metal ion leads to increased polarization of the hydrogen atoms. Consequently, the oxidized species is increasingly stabilized with increasing donor strength of the solvent :

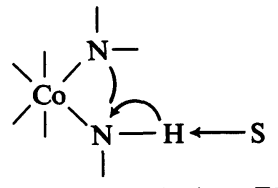

EPA EPD

The magnitude of the shifts is quite high, e.g. half-wave potentials in acetonitrile and dimethylformic amide differ by $0.36 \mathrm{~V}$, which corresponds to a free energy difference of $8.3 \mathrm{kcal} / \mathrm{mol}^{55}$.

The values of the formation constants of the outer-sphere complex $\left[\mathrm{Co}(\mathrm{en}){ }_{2} \mathrm{Cl}_{2}\right] \mathrm{Cl}$ are influenced both by outer-sphere coordination at the acidic hydrogen atoms and by solvation of the chloride ion. Values $K_{\text {out }}$ in DMF, DMA and DMSO primarily reflect the differences in anion solvating power, since the donicities of these solvents are very similar. $K_{\text {out }}$ decreases in the order DMA > DMF > DMSO, which corresponds to the increase in anion solvating power. The smallest value of $K_{\text {out }}$ is observed in methanol. Methanol behaves as a rather weak donor (see Section VII) but acts as a very strong solvating solvent towards anions, owing to its ability to form hydrogen bonds. In contrast, $K_{\text {out }}$ is largest in sulpholane, which is the weakest donor in the series. Note that $K_{\text {out }}$ in sulpholane is larger by more than two powers of ten than in methanol, which indicates complete failure of elementary electrostatic models in these systems. Sulpholane has a higher dipole moment and a higher dielectric constant than methanol.

\section{KINETICS OF SUBSTITUTION REACTIONS}

Recent investigations of the kinetics of substitution reactions of various metal complexes have established a close relationship between chemical reactivity and solvent coordination properties.

Substitution reactions of octahedral complexes of the type

$$
\left[\mathrm{ML}_{6}\right]^{2+}+\mathrm{X}^{-} \rightleftharpoons\left[\mathrm{ML}_{5} \mathrm{X}\right]^{+}+\mathrm{L}
$$

have been investigated by Hoffmann and co-workers ${ }^{57-59}$. L denotes a solvent molecule and $\mathrm{X}^{-}$an anionic substituent. These reactions are considered to proceed by a two-step mechanism with rapid formation of an encounter complex and subsequent dissociation of the ligand to be substituted $^{60}$. The latter step is considered to be rate-determining:

$$
\left[\mathrm{ML}_{6}\right]^{2+}+\mathrm{X}^{-} \stackrel{K_{0}}{\rightleftharpoons}\left[\mathrm{ML}_{6} \ldots \mathrm{X}\right]^{+} \underset{k_{-1}}{\stackrel{k_{1}}{\rightleftharpoons}}\left[\mathrm{ML}_{5} \mathrm{X}\right]^{+}+\mathrm{L}
$$


Figure 8 shows the relationship between dissociation rate constant $k_{-1}$ and donicity for solvolysis of $\left[\mathrm{NiL}_{5}(\mathrm{TFA})\right]^{+}$in different solvents $(\mathrm{TFA}=$ trifluoroacetate anion) ${ }^{59}$. Rate constants increase with increasing donicity.

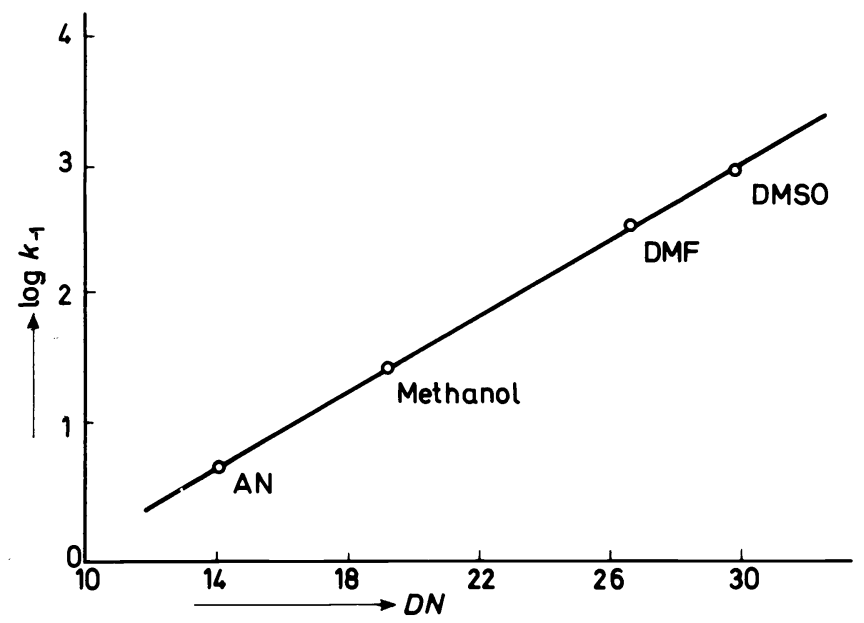

Figure 8. Dissociation rate constants $k_{-1}$ for the solvolysis of $\left[\mathrm{NiL}_{5}(\mathrm{TFA})\right]^{+}$in various donor solvents as a function of $D N$ (TFA = trifluoroacetate anion)

Increasing donicity of $L$ leads to an increase in electron density at $M$ and therefore to a decrease in the EPA properties of group $\mathrm{ML}_{5}$. Consequently, the $\mathrm{M}-\mathrm{X}$ bond is increasingly weakened with increasing donor strength of $\mathrm{L}^{43}$.

The relationship between chemical reactivity and coordinating properties of the solvents is further demonstrated by the reaction between $\mathrm{SbCl}_{5}$ and $\mathrm{Ph}_{3} \mathrm{CCl}^{43,61}$ :

$$
\mathrm{SbCl}_{5} \cdot \mathrm{L}+\mathrm{Ph}_{3} \mathrm{CCl} \underset{k_{21}}{\stackrel{k_{12}}{\rightleftharpoons}}\left[\mathrm{Ph}_{3} \mathrm{C}^{+} \mathrm{SbCl}_{6}^{-}\right]^{0}+\mathrm{L}
$$

The rate-determining step of the reaction is believed to be the rupture of the coordinate bond between antimony and the solvent molecule ${ }^{61}$. Figure 9 reveals that the over-all rate constant $k_{12}$ for formation of the hexachloroantimonate ion increases with decreasing donicity of the solvent. No strictly linear correlation is observed. In fact, $k_{12}$ is a composite constant and may therefore contain contributions from other solvent properties. As previously stated, outer-sphere interactions between Co(III)-ammine complexes and bases are due to the acidic nature of the ammine hydrogen atoms. It is therefore expected that outer-sphere interactions play an important role in the kinetic behaviour of these complexes.

Rates of solvolysis and isomerization of cis- and trans- $\left[\mathrm{Co}(\mathrm{en})_{2} \mathrm{Cl}_{2}\right]^{+}$have been determined by Watts $e t$ al. in a number of aprotic and protic solvents and have been discussed in terms of Parker's solvent activity coefficients ${ }^{62}$. The authors arrive at the conclusion that isomerization in methanol and sulpholane proceeds by an SN1 mechanism, but that solvolysis in DMF and DMSO probably involves a bimolecular substitution step. 


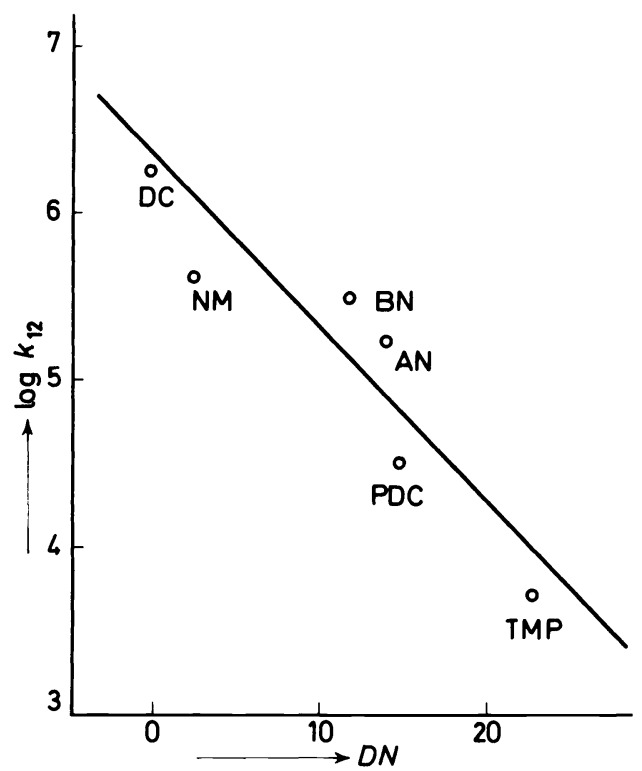

Figure 9. Rate constants for the formation of trityl hexachloroantimonate(V) from trityl chloride and antimony pentachloride in various donor solvents as a function of $D N$

On the other hand, it is known that most substitution reactions of $\mathrm{Co}$ (III) complexes can be understood in terms of Langford's dissociative interchange $\left(I_{\mathrm{d}}\right)$ mechanism ${ }^{63,64}$. In this mechanism substitution is preceded by rapid formation of an encounter complex followed by the rearrangement of this complex in a rate-determining dissociative step ${ }^{65}$. In view of the results obtained in the polarographic reduction of $\left[\mathrm{Co}(\mathrm{en})_{3}\right]^{3+}$, which have clearly revealed the importance of outer-sphere coordination at the acidic hydrogen atoms, an attempt has been made to reinterpret the work of Watts. Data from reference 62 have been recalculated using improved solvent activity coefficients for $\mathrm{Cl}^{-}$and are listed in Table 6. Symbol c refers to cis$\left[\mathrm{Co}(\mathrm{en})_{2} \mathrm{Cl}_{2}\right]^{+}$, symbol c ${ }^{*}$ to a model SN1 transition state $\left.\left[\mathrm{Co}^{+\delta^{+}} \text {en }\right)_{2} \mathrm{Cl} \ldots . \mathrm{Cl}^{-}\right]^{+}$, which, in a qualitative way, may be considered as an adequate model for

Table 6. Chemical potentials of $c i s-\left[\mathrm{Co}(\mathrm{en})_{2} \mathrm{Cl}_{2}\right]^{+}\left(\mu_{\mathrm{c}}\right)$ and of the corresponding transition state cation $\left(\mu_{\mathrm{c} \neq}\right)$ in various solvents at $25^{\circ} \mathrm{C}$. The chemical potential $\mu_{\mathrm{c}}$ in DMF has been arbitrarily taken

as zero

\begin{tabular}{lcc}
\hline Solvent & $\mu_{\mathrm{c}}(\mathrm{kcal})$ & $\mu_{\mathrm{c} \neq}(\mathrm{kcal})$ \\
\hline DMSO & -1.22 & 23.43 \\
DMF & 0.0 & 23.57 \\
TMS & +2.45 & 29.55 \\
Water & 3.54 & 25.75 \\
Methanol & 6.53 & 30.37 \\
\hline
\end{tabular}


transition states involved in the $I_{\mathrm{d}}$ pathway. The transition state cation is characterized by increased negative charge at the leaving $\mathrm{Cl}^{-}$and by increased positive charge at the coordination centre. The most significant results from Table 6 are shown in Figure 10. Figure 10(a) reveals that

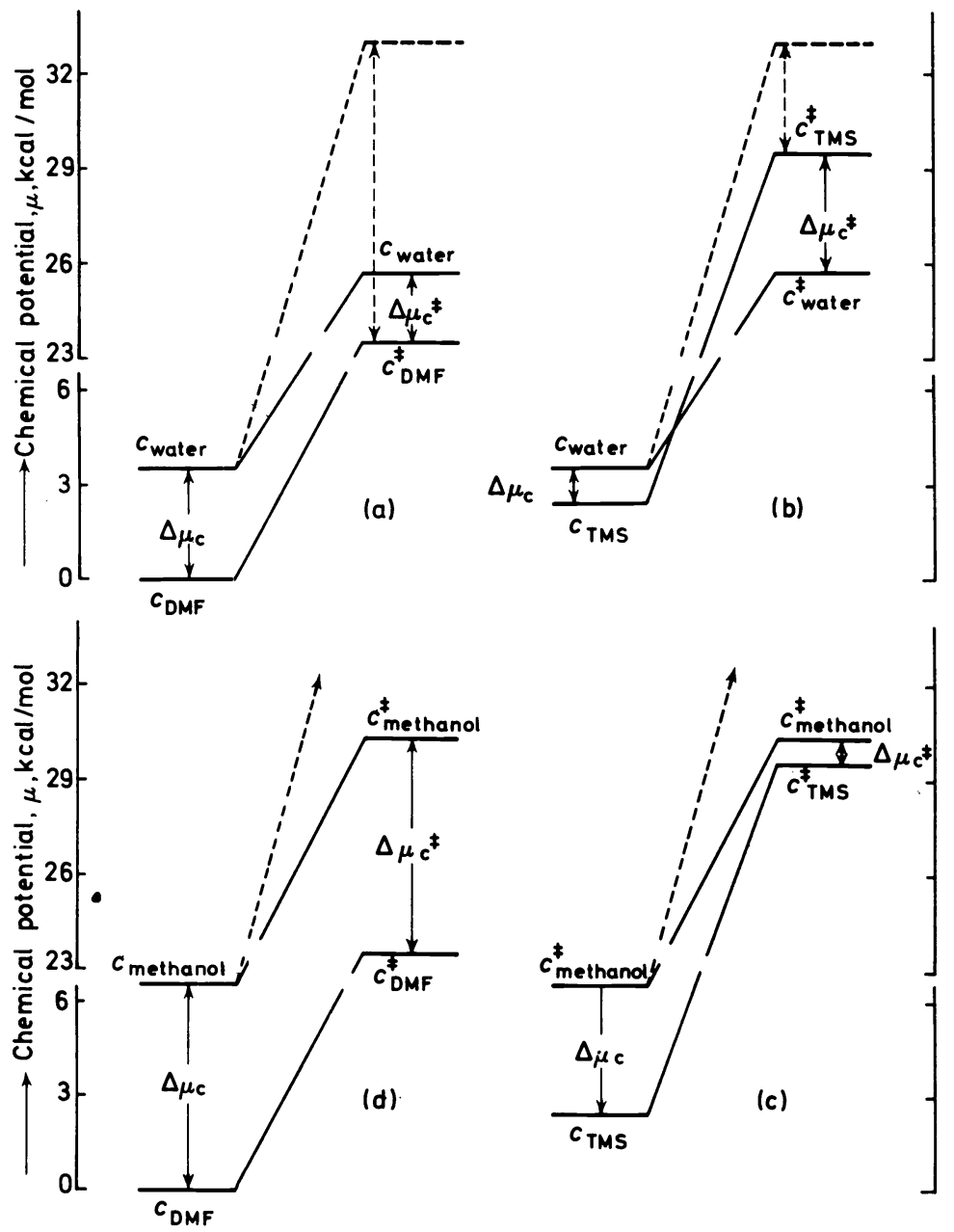

Figure 10. Chemical potentials of cis-[Co(en $\left.)_{2} \mathrm{Cl}_{2}\right]^{+}$and of the corresponding activated complex in several solvents, assuming a model SN1 transition state

$\left[\mathrm{Co}(\mathrm{en})_{2} \mathrm{Cl}_{2}\right]^{+}$is more strongly solvated in DMF than in water. This must be ascribed to the dominating influence of outer-sphere coordination at the hydrogen atoms of the complex cation, DMF behaving as a much stronger donor than water. The expected influence of outer-sphere coordination at the chlorine atoms is comparatively small, because the base properties of the chloride ions are strongly reduced by coordination to the $\mathrm{Co}$ (III) ion.

In the transition state the leaving $\mathrm{Cl}^{-}$ion carries a high negative partial 
charge. Since water is a strong hydrogen-bonding solvent, it was proposed that in the case of a SN1 mechanism the transition state cation should be more strongly solvated in water than in $\mathrm{DMF}^{62}$. This argument is true but does not allow for the influence of outer-sphere coordination at the hydrogen atoms. Development of positive charge at the coordination centre of the transition state cation increases the acidity of the hydrogen atoms. Consequently, if there were no simultaneous influence of solvation of the leaving ligand, the energy difference $\Delta \mu$ should be considerably greater for the transition state than for the ground state. This is indicated in Figure 10(a) by the dotted lines. The effect is partly compensated, but not necessarily overcompensated, by increased solvation of $\mathrm{Cl}^{-}$in the transition state cation in water. Comparison of the behaviour in water and sulpholane (TMS) supports this view. Again, TMS behaves as a stronger donor than water, so that in absence of anion solvation $\Delta \mu_{\mathrm{c} \neq}$ should be greater than $\Delta \mu_{\mathrm{c}}$ (again indicated by the dotted lines). Since, however, TMS $(D N=14.8)$ is a much weaker donor than DMF ( $D N=26.6$, the outer-sphere EPD effect is much less pronounced and is now actually overcompensated by the strong solvation of the leaving ligand in water. Consequently, the transition state cation is more strongly solvated in water than in TMS. No reversal in the relative stability order is observed for methanol and TMS, which is in agreement with the fact that $\mathrm{Cl}^{-}$is less effectively solvated by methanol than by water. Increasing solvation of $\mathrm{Cl}^{-}$in the transition state cation therefore only results in a lowering of the free energy difference $\Delta \mu_{\mathrm{c} *}$ as compared with $\Delta \mu_{\mathrm{c}}$.

The situation in methanol and DMF is consistent with this behaviour. DMF is a stronger donor than TMS, so that the increased outer-sphere EPD effect at the hydrogen atoms is just sufficiently large to nullify the effect of increased anion solvation in methanol. Consequently, $\Delta \mu$ remains essentially unchanged in going from the ground state to the transition state.

The same over-all pattern is observed if DMF is replaced by DMSO in Figures 10(a) and 10(d). It therefore appears that, in view of the important role of the outer-sphere EPD effect, the kinetic behaviour of $\left[\mathrm{Co}(\mathrm{en}){ }_{2} \mathrm{Cl}_{2}\right]^{+}$ in different solvents is at least not inconsistent with a common SN1 transition state model.

An interesting observation is made, if the relative stabilities of cis$\left[\mathrm{Co}(\mathrm{en}){ }_{2} \mathrm{Cl}_{2}\right]^{+}$are compared in different solvents. As previously stated, methanol and water apparently behave as weaker donors than sulpholane. On first consideration this appears to be in contradiction with the coordination chemical approach, since the donicity of sulpholane is lower than the donicities of methanol and water. However, it appears that in the case of methanol and water the interaction energy between a solvent molecule and a polarized hydrogen atom of an ethylenediamine group is not sufficiently high to overcome the hydrogen bond energy of the associated molecules. This implies that in the case of associated liquids donicity values as determined towards excess $\mathrm{SbCl}_{5}$ in 1,2-dichloroethane cannot be confidently used as a measure of the donor properties of the solvent. In fact, in associated liquids the effective donor strength of the molecules turns out to be a function of the acceptor (EPA) properties of the substrate. Strong EPA units may cause reorientation of solvent molecules. Owing to outer-sphere interactions between solvent molecules of the inner and outer hydration shells, the effective 


\section{IONIC EQUILIBRIA IN DONOR SOLVENTS}

donor strength of the solvent molecules may considerably exceed the EPD strength of the isolated (unassociated) molecules. If, on the other hand, the interaction energy between substrate and solvent molecules is small as compared with the energy of the bridge bonds, then the solvent will behave as a much weaker donor than would be expected according to its donicity.

These effects appear to be of general importance for the understanding of chemical equilibria and reaction rates in amphoteric solvents or mixtures of amphoteric and non-amphoteric solvents. In such solvent systems donicity values cannot be used with confidence but are still useful, since deviations from the expected behaviour may serve as a diagnostic tool for the nature of substrate-solvent interactions.

\section{QUANTITATIVE TREATMENT OF CHEMICAL EQUILIBRIA AND REACTION RATES}

So far, the discussion has been restricted to a qualitative consideration of chemical reactions. A new approach, based on coordination chemical and extrathermodynamic considerations, has recently been developed which allows a quantitative treatment of chemical equilibria and reaction rates ${ }^{67}$. The applicability of this approach will be discussed by means of the trichlorotetrachlorocobaltate(II) equilibrium in various non-aqueous solvents:

$$
\begin{gathered}
{\left[\mathrm{CoCl}_{3} \cdot \mathrm{S}\right]^{-}+\mathrm{Cl}^{-} \rightleftharpoons\left(\mathrm{CoCl}_{4}\right]^{2-}+\mathrm{S}} \\
K_{\mathrm{f}}^{\mathrm{s}}=\frac{\left[\mathrm{CoCl}_{4}^{2-}\right]}{\left[\mathrm{CoCl}_{3} \cdot \mathrm{S}^{-}\right] \cdot\left[\mathrm{Cl}^{-}\right]} \quad \Delta G^{\mathrm{S}}=-R T \ln K_{\mathrm{f}}^{\mathrm{s}}
\end{gathered}
$$

Thermodynamic data for reaction (6) are listed in Table 7.

Table 7. Free energies of formation and formation constants for reaction 6 in various non-aqueous solvents at zero ionic strength and $25^{\circ} \mathrm{C}^{68}$

\begin{tabular}{lcc}
\hline Solvent & $\Delta G^{\mathrm{s}}(\mathrm{kcal} / \mathrm{mol})$ & $K_{\mathrm{f}}^{\mathrm{S}}\left(1^{1} \mathrm{~mol}^{-1}\right)$ \\
\hline NM & $-6.59 \pm 0.04$ & $(7.0 \pm 0.5) \times 10^{4}$ \\
BN & $-4.82 \pm 0.01$ & $(3.5 \pm 0.1) \times 10^{3}$ \\
AN & $-3.92 \pm 0.02$ & $(7.7 \pm 0.2) \times 10^{2}$ \\
Acetone & $-4.69 \pm 0.04$ & $(2.8 \pm 0.2) \times 10^{3}$ \\
DMF & $-1.64 \pm 0.07$ & $16 \pm 2$ \\
DMA & $-2.05 \pm 0.07$ & $32 \pm 4$ \\
\hline
\end{tabular}

The data show that the stability of the tetrachlorocobaltate(II)ion on the whole decreases with increasing donicity of the solvents. The ion $\mathrm{CoCl}_{4}^{2-}$ is most stable in NM, which is a poor donor, and is least stable in DMF and DMA, which are stronger donor solvents. Intermediate values of $K_{\mathrm{f}}^{\mathrm{s}}$ are observed in solvents with medium donor strength, namely BN, AN and acetone. On the other hand, a number of irregularities can be observed. For example, $\mathrm{CoCl}_{4}^{2-}$ is more stable in acetone than in $\mathrm{AN}$, although acetone 


\section{U. MAYER}

is the stronger donor. The same applies to DMF and DMA. The behaviour of water appears to be quite irregular. Although water has a donicity similar to that of acetone, $\mathrm{CoCl}_{4}^{2-}$ is unstable in this solvent ${ }^{69}$.

These irregularities reveal that, besides the EPD strength of the solvent, there are still other factors which contribute to the stability of the complex ions. This is illustrated by the thermochemical cycle (8), which shows the relationship between the standard free energy of formation of the tetrachlorocobaltate ion in solution and in the gas phase.

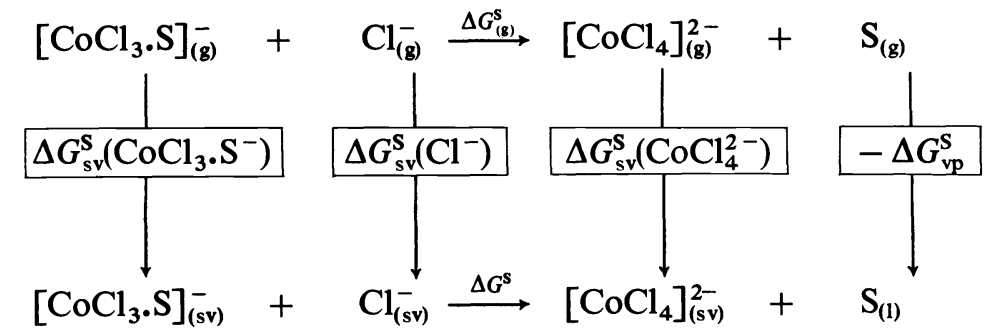

The following equation is obtained:

$$
\Delta G_{(\mathrm{g})}^{\mathrm{s}}=\Delta G^{\mathrm{S}}+\Delta G_{\mathrm{sv}}^{\mathrm{s}}\left(\mathrm{Cl}^{-}\right)+\Delta G_{\mathrm{sv}}^{\mathrm{S}}\left(\mathrm{CoCl}_{3} \cdot \mathrm{S}^{-}\right)-\Delta G_{\mathrm{sv}}^{\mathrm{s}}\left(\mathrm{CoCl}_{4}^{2-}\right)+\Delta G_{\mathrm{vp}}^{\mathrm{s}}
$$

It is realized that $\Delta G^{\mathrm{S}}$ depends on $\Delta G_{(\mathrm{g})}^{\mathrm{S}}$, on the free energies of solvation of the anionic species and on the standard free energy $\Delta G_{\mathrm{vp}}^{\mathrm{s}}$ of vaporization. In contrast, $\Delta G_{(\mathrm{g})}^{\mathrm{s}}$ only depends on the donor properties of the solvent. This can be shown by resolving reaction (10) into the component reactions (11) and (12):

$$
\begin{gathered}
{\left[\mathrm{CoCl}_{3} \cdot \mathrm{S}\right]_{(\mathrm{g})}^{-}+\mathrm{Cl}_{(\mathrm{g})}^{-} \rightarrow\left[\mathrm{CoCl}_{4}\right]_{(\mathrm{g})}^{2-}+\mathrm{S}_{(\mathrm{g})}, \Delta H_{(\mathrm{g})}^{\mathrm{s}}} \\
{\left[\mathrm{CoCl}_{3}\right]_{(\mathrm{g})}^{-}+\mathrm{S}_{(\mathrm{g})} \rightarrow\left[\mathrm{CoCl}_{3} \cdot \mathrm{S}\right]_{(\mathrm{g})}^{-}, \Delta H^{\prime}} \\
{\left[\mathrm{CoCl}_{3}\right]_{(\mathrm{g})}^{-}+\mathrm{Cl}_{(\mathrm{g})}^{-} \rightarrow\left[\mathrm{CoCl}_{4}\right]_{(\mathrm{g})}^{2-}, \Delta H^{\prime \prime}}
\end{gathered}
$$

$\Delta H^{\prime}$ is expected to be directly proportional to the donicity of the solvent molecules:

$$
\Delta H^{\prime}=-f \times D N
$$

The coefficient $f$ represents a measure of the acceptor strength of the gaseous $\mathrm{CoCl}_{3}^{-}$ion relative to $\mathrm{SbCl}_{5}$.

According to

$$
\Delta H_{(\mathrm{g})}^{\mathrm{s}}=-\Delta H^{\prime}+\Delta H^{\prime \prime}
$$

one obtains

$$
\Delta G_{(\mathbf{g})}^{\mathrm{s}}=f \times D N+\Delta H^{\prime \prime}-T \Delta S_{(\mathbf{g})}^{\mathrm{s}}
$$

Since the entropy change $\Delta S_{(\mathrm{g})}^{\mathrm{S}}$ always refers to the same type of gas phase reaction, it may be considered as approximately constant for different molecules S. Consequently, the free energy difference of the gas phase reactions for a solvent $\mathrm{S}$ and a reference solvent $\mathrm{R}$ is given by:

$$
\Delta \Delta G_{(\mathrm{g})}=\Delta G_{(\mathrm{g})}^{\mathrm{S}}-\Delta G_{(\mathrm{g})}^{\mathrm{R}}=f \times\left(D N^{\mathrm{S}}-D N^{\mathrm{R}}\right)=f \times \Delta D N
$$


or

$$
\Delta \Delta G_{(\mathrm{g})}=f \times \Delta D N
$$

The corresponding free energy difference for the formation of $\mathrm{CoCl}_{4}^{2-}$ in solution is obtained from equation (9):

$$
\begin{gathered}
\Delta \Delta G_{(\mathrm{g})}=\Delta G^{\mathrm{S}}-\Delta G^{\mathrm{R}}+\Delta G_{\mathrm{sv}}^{\mathrm{S}}\left(\mathrm{Cl}^{-}\right)-\Delta G_{\mathrm{sv}}^{\mathrm{R}}\left(\mathrm{Cl}^{-}\right)+\Delta G_{\mathrm{sv}}^{\mathrm{S}}\left(\mathrm{CoCl}_{3} \cdot \mathrm{S}^{-}\right) \\
-\Delta G_{\mathrm{sv}}^{\mathrm{R}}\left(\mathrm{CoCl}_{3} \cdot \mathrm{R}^{-}\right)-\left\{\Delta G_{\mathrm{sv}}^{\mathrm{S}}\left(\mathrm{CoCl}_{4}^{2-}\right)-\Delta G_{\mathrm{sv}}^{\mathrm{R}}\left(\mathrm{CoCl}_{4}^{2-}\right)\right\} \\
+\Delta G_{\mathrm{vp}}^{\mathrm{S}}-\Delta G_{\mathrm{vp}}^{\mathrm{R}}
\end{gathered}
$$

Using the same nomenclature as in equation (16), equation (18) reduces to:

$$
\begin{array}{r}
\Delta \Delta G_{(\mathrm{g})}=f \times \Delta D N=\Delta \Delta G+\Delta \Delta G_{\mathrm{sv}}\left(\mathrm{Cl}^{-}\right)+\Delta \Delta G_{\mathrm{sv}}\left(\mathrm{CoCl}_{3} \cdot \mathrm{S}^{-}\right) \\
-\Delta \Delta G_{\mathrm{sv}}\left(\mathrm{CoCl}_{4}^{2-}\right)+\Delta \Delta G_{\mathrm{vp}}
\end{array}
$$

As previously stated (see Section 3, Table 2), the free energies of solvation of the chloride ion can be determined by means of extrathermodynamic methods. The standard free energies of vaporization are given by equation (20), in which $p^{\mathbf{S}}$ denotes the equilibrium vapour pressure of the solvent $\mathbf{S}$ at $298 \mathrm{~K}$ :

$$
\Delta G_{\mathrm{vp}}^{\mathrm{S}}=-R T \ln p^{\mathrm{s}}
$$

Values $\Delta \Delta G_{\mathrm{vp}}$ have been calculated for various solvents and are listed in Table $8^{67}$.

Table 8. Standard free energies of vaporization of various solvents $\mathrm{S}$ referred to reference solvent acetonitrile $(T=298 \mathrm{~K})$

\begin{tabular}{lclc}
\hline Solvent & $\Delta G_{\mathrm{vp}}^{\mathrm{S}}-\Delta G_{\mathrm{vp}}^{\mathrm{AN}}$ & Solvent & $\Delta G_{\mathrm{vp}}^{\mathrm{S}}-\Delta G_{\mathrm{vp}}^{\mathrm{AN}}$ \\
\hline NM & 0.52 & DMF & 1.88 \\
AN & 0.00 & DMA & 2.49 \\
TMS & 5.40 & DMSO & 2.95 \\
Acetone & -0.54 & HMPA & 4.31 \\
\hline
\end{tabular}

The remaining terms in equation (19), namely $\Delta \Delta G_{\text {sv }}\left(\mathrm{CoCl}_{3} \cdot \mathrm{S}^{-}\right)$and $\Delta \Delta G_{\text {sv }}\left(\mathrm{CoCl}_{4}^{2-}\right)$, cannot be experimentally determined. However, it can be theoretically shown that these quantities are related to the free energy of solvation of the chloride ion ${ }^{67}$. The basic concept of the theory can be illustrated best by considering the curves for the polarographic reduction of metal ions, shown in Figure 4. As previously stated, the free energy change $\Delta G_{\text {red }}$ for the reduction of a given metal ion depends on the free energy of solvation $\Delta G_{\mathrm{sv}}\left(\mathrm{M}^{z+}\right)$. Consequently, the difference in free energies for two different solvents $S_{1}$ and $S_{2}$ is given by:

$$
\Delta G_{\text {red }}^{\mathrm{S}_{1}}-\Delta G_{\text {red }}^{\mathrm{S}_{2}}=-\left\{\Delta G_{\mathrm{sv}}^{\mathrm{S}_{1}}\left(\mathrm{M}^{\mathbf{z}+}\right)-\Delta G_{\mathrm{sv}}^{\mathrm{S}_{2}}\left(\mathrm{M}^{z+}\right)\right\}
$$

* In $\Delta \Delta G_{\mathrm{sv}}\left(\mathrm{CoCl}_{3} . \mathrm{S}^{-}\right)$, the symbol $\mathrm{S}$ stands both for the solvent $\mathrm{S}$ and the reference solvent $\mathrm{R}$. 
or

$$
\Delta \Delta G_{\mathrm{red}}=-\Delta \Delta H_{\mathrm{sv}}\left(\mathrm{M}^{z+}\right)+\mathrm{T} . \Delta \Delta S_{\mathrm{sv}}\left(\mathrm{M}^{z+}\right)
$$

Since, according to Figure $4, \Delta G_{\text {red }}$ is an approximately linear function of the donicity $D N$, one might expect that the solvation enthalpies $\Delta H_{\text {sv }}\left(\mathrm{M}^{z+}\right)$ of a given metal ion in different solvents are directly proportional to the donicities of the solvents:

$$
\Delta H_{\mathrm{sv}}\left(\mathrm{M}^{z+}\right)=- \text { prop. } D N
$$

or

$$
\Delta \Delta G_{\text {red }}=\text { prop. }\left(D N^{\mathrm{s}_{1}}-D N^{\mathrm{S}_{2}}\right)+T \cdot \Delta \Delta S_{\mathrm{sv}}\left(\mathrm{M}^{z+}\right)
$$

However, it can be easily demonstrated that equation (23) is incompatible with the experimental findings. Let us assume that a divalent metal ion is reduced on the one hand in water and on the other hand in a very poor donor solvent such as nitromethane. If equations (23) and (24) were correct, the free energy difference $\Delta \Delta G_{\text {red }}$ should roughly correspond to the hydration energy of the metal ion. The latter value amounts to about $400-500 \mathrm{kcal} / \mathrm{mol}$, which corresponds to a potential difference $\Delta E_{\text {red }}$ of about $10 \mathrm{~V}$. In fact, the experimental values are lower by a power of ten. This clearly shows that only a small fraction of the energy change associated with the transfer of an ion from the gas phase into the solution can be ascribed to specific ion solvent interactions. The main contribution to the solvation energy undoubtedly arises from the dielectric polarization of the solvent molecules and in principle may be described by the Born equation (25) or suitable modifications thereof.

$$
\Delta G_{\mathrm{sv}}=-\frac{N(z e)^{2}}{2 r}\left\{1-\frac{1}{\varepsilon}\right\}
$$

The main point is that this energy contribution is large, but unspecific as compared with the energy changes associated with the specific ion solvent interactions.

Consequently, $\Delta G_{\mathrm{dv}}\left(M^{z+}\right)$ may be best represented by ${ }^{67}$ :

$$
\Delta G_{\mathrm{sv}}\left(\mathrm{M}^{z+}\right)=\left[\Delta G_{\mathrm{sv}}\left(\mathrm{M}^{z+}\right)\right]_{\mathrm{dp}}+\left[\Delta G_{\mathrm{sv}}\left(\mathrm{M}^{z+}\right)\right]_{\mathrm{sp}}
$$

The term $\left[\Delta G_{\mathrm{sv}}\left(\mathrm{M}^{z+}\right)\right]_{\mathrm{sp}}(\mathrm{dp}=$ dielectric polarization $)$ is considered to be approximately constant for solvents with similar dielectric constants.

The specific interaction energy term $\left[\Delta G_{\mathrm{sv}}\left(\mathrm{M}^{z+}\right)\right]_{\mathrm{sp}}$ may be represented by equation (27), which has been obtained from coordination chemical considerations :

$$
\left[\Delta G_{\mathrm{sv}}\left(\mathrm{M}^{z+}\right)\right]_{\mathrm{sp}}=\phi_{\mathrm{I}} \times \phi_{\mathrm{S}}
$$

The functions $\phi_{\mathrm{I}}$ and $\phi_{\mathrm{S}}$ depend only on the nature of the ion and the solvent, respectively ${ }^{67}$. 


\section{IONIC EQUILIBRIA IN DONOR SOLVENTS}

Applying the same considerations to the trichloro-tetrachlorocobaltate(II) equilibrium, one obtains:

$$
\begin{gathered}
\Delta G_{\mathrm{sv}}^{\mathrm{s}}\left(\mathrm{Cl}^{-}\right)=\left[\Delta G_{\mathrm{sv}}\left(\mathrm{Cl}^{-}\right)\right]_{\mathrm{dp}}+\left[\Delta G_{\mathrm{sv}}^{\mathrm{s}}\left(\mathrm{Cl}^{-}\right)\right]_{\mathrm{sp}} \\
\Delta G_{\mathrm{sv}}^{\mathrm{s}}\left(\mathrm{CoCl}_{4}^{2-}\right)=\left[\Delta G_{\mathrm{sv}}\left(\mathrm{CoCl}_{4}^{2-}\right)\right]_{\mathrm{dp}}+\left[\Delta G_{\mathrm{sv}}^{\mathrm{s}}\left(\mathrm{CoCl}_{4}^{2-}\right)\right]_{\mathrm{sp}}
\end{gathered}
$$

According to equation (27), the specific solvation energy term for the tetrachlorocobaltate(II) ion can be represented as :

$$
\left[\Delta G_{\mathrm{sv}}^{\mathrm{s}}\left(\mathrm{CoCl}_{4}^{2-}\right)\right]_{\mathrm{sp}}=\alpha_{1} \times\left[\Delta G_{\mathrm{sv}}^{\mathrm{s}}\left(\mathrm{Cl}^{-}\right)\right]_{\mathrm{sp}}
$$

The coefficient $\alpha_{1}$ is independent of the solvent. Similarly, the free energy of solvation of the trichlorocobaltate(II) ion can be related to that of the chloride ion by introducing a coefficient $\alpha_{2}$ which is again independent of the solvent. However, the free energy of solvation of the trichlorocobaltate(II) ion contains an additional term, which arises from the interaction of the coordinated solvent molecule with bulk solvent molecules. This term is apparently related to the standard free energy of vaporization of the solvent. Since the coordinated solvent molecule is partially shielded by the $\mathrm{CoCl}_{3}^{-}$ group, the interaction energy must be smaller than $\Delta G_{\mathrm{vp}}^{\mathrm{S}}$ and may therefore be represented by ${ }^{67}$ :

$$
\overline{\Delta G_{\mathrm{sv}}^{\mathrm{s}}}\left(\mathrm{CoCl}_{3} \cdot \mathrm{S}^{-}\right)=-\beta_{2} \times \Delta G_{\mathrm{vp}}^{\mathrm{s}}
$$

The coefficient $\beta_{2}$ is tentatively assumed to be independent of the solvent.

The total free energy of solvation of the trichlorocobaltate(II) ion is then given by:

$$
\begin{array}{r}
\Delta G_{\mathrm{sv}}^{\mathrm{s}}\left(\mathrm{CoCl}_{3} \cdot \mathrm{S}^{-}\right)=\left[\Delta G_{\mathrm{sv}}\left(\mathrm{CoCl}_{3} \cdot \mathrm{S}^{-}\right)\right]_{\mathrm{dp}}+\alpha_{2} \times\left[\Delta G_{\mathrm{sv}}^{\mathrm{s}}\left(\mathrm{Cl}^{-}\right)\right]_{\mathrm{sp}} \\
-\beta_{2} \times \Delta G_{\mathrm{vp}}^{\mathrm{s}}
\end{array}
$$

Applying equations (28)-(32) to a reference solvent $R$, one obtains for the differences of the solvation energies:

$$
\begin{gathered}
\Delta \Delta G_{\mathrm{sv}}\left(\mathrm{Cl}^{-}\right)=\left[\Delta \Delta G_{\mathrm{sv}}\left(\mathrm{Cl}^{-}\right)\right]_{\mathrm{sp}} \\
\Delta \Delta G_{\mathrm{sv}}\left(\mathrm{CoCl}_{4}^{2-}\right)=\alpha_{1} \times \Delta \Delta G_{\mathrm{sv}}\left(\mathrm{Cl}^{-}\right) \\
\Delta \Delta G_{\mathrm{sv}}\left(\mathrm{CoCl}_{3} \cdot \mathrm{S}^{-}\right)=\alpha_{2} \times \Delta \Delta G_{\mathrm{sv}}\left(\mathrm{Cl}^{-}\right)-\beta_{2} \times \Delta \Delta G_{\mathrm{vp}}
\end{gathered}
$$

Substituting equations (34) and (35) into equation (19), one obtains:

$$
\begin{aligned}
\Delta \Delta G_{(\mathbf{g})}=f \times \Delta D N=\Delta \Delta G+\left(1+\alpha_{2}-\alpha_{1}\right) \times \Delta \Delta G_{\mathrm{sv}}\left(\mathrm{Cl}^{-}\right) & \\
& +\left(1-\beta_{2}\right) \times \Delta \Delta G_{\mathrm{vp}}
\end{aligned}
$$

or

$$
\Delta \Delta G_{(\mathrm{g})}=f \times \Delta D N=\Delta \Delta G+a \times \Delta \Delta G_{\mathrm{sv}}\left(\mathrm{Cl}^{-}\right)+b \times \Delta \Delta G_{\mathrm{vp}}
$$

with

$$
a=1+\alpha_{2}-\alpha_{1}
$$

\footnotetext{
* See footnote to equation (19).
} 
and

$$
b=1-\beta_{2}
$$

Experimentally the following equation has been found ${ }^{67}$ :

$$
\Delta \Delta G_{(\mathrm{g})}=0.34 \times \Delta D N=\Delta \Delta G+0.53 \times \Delta \Delta G_{\mathrm{sv}}\left(\mathrm{Cl}^{-}\right)+0.50 \times \Delta \Delta G_{\mathrm{vp}}
$$

The coefficient $f=0.34$ represents a measure of the acceptor strength of the gaseous $\mathrm{CoCl}_{3}^{-}$ion relative to $\mathrm{SbCl}_{5}$ and indicates that this ion is a much weaker acceptor than $\mathrm{SbCl}_{5}$. This agrees with the observation that the hexachloroantimonate( $\mathrm{V})$ ion is more stable in solution than the tetrachlorocobaltate(II) ion.

The value $b=0.5$ shows that the solvation energy of the solvent molecule coordinated to the $\mathrm{CoCl}_{3}^{-}$group is only half as large as that of an uncoordinated solvent molecule. Structural considerations suggest that the steric requirement of the $\mathrm{CoCl}_{3}^{-}$group within the potential field of the coordinated solvent molecule is nearly constant and indeed corresponds to a solid angle of about $2 \pi$ steradians. Consequently constant $\beta_{2}$ and $b$ values are observed for different solvent molecules.

The coefficient $a=0.53$ is composed of the constants $\alpha_{1}$ and $\alpha_{2}$, which are related to the charge distribution within the corresponding complex ions $^{67}$.

The results are graphically shown in Figure 11, in which the right-hand side of equation (39) has been plotted against $\triangle D N$. Unlike the free energies of formation in solution, the free energies of formation in the gas phase

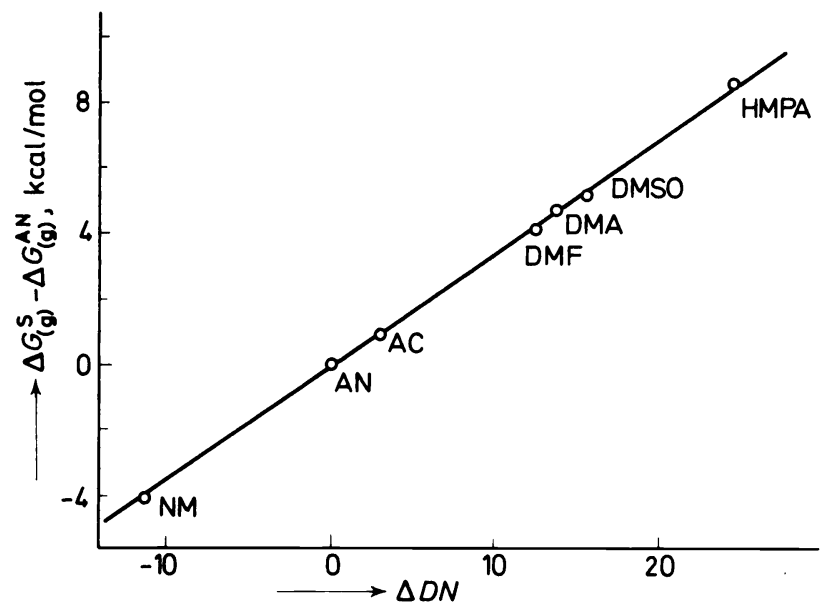

Figure 11. Free energies of formation of $\left[\mathrm{CoCl}_{4}\right]^{2-}$ from $\left[\mathrm{CoCl}_{3} . \mathrm{S}\right]^{-}$and $\mathrm{Cl}^{-}$in the gas phase as a function of $D N$

increase linearly with increasing donicity of the solvents. The range of stability constants covered by equation (39) is about five powers of ten in 
solution! The values given for DMSO and HMPA have been calculated from equilibrium data available in the literature and agree very well with the theoretical values predicted from the observed linear relationship ${ }^{70,71 *}$.

Equation (39) can also be used to calculate equilibrium constants for other solvents, provided that the quantities $\Delta D N, \Delta \Delta G_{\mathrm{sv}}\left(\mathrm{Cl}^{-}\right)$and $\Delta \Delta G_{\mathrm{vp}}$ are known. This is particularly useful in the case of water, since the stability constant cannot be directly determined in this solvent. As previously stated (see Section VII), the donicity of liquid water is not known with certainty. However, a reasonable estimate may be obtained by use of the value $D N=18$ for the unassociated solvent molecules. For $D N=18$ a value $\Delta \Delta G_{(\mathrm{g})}=1.3$ $\mathrm{kcal} / \mathrm{mol}$ is obtained from Figure 11 . Using the values $\Delta \Delta G_{\mathrm{vp}}=0.78$ (ref. 67) and $\Delta \Delta G_{\mathrm{sv}}\left(\mathrm{Cl}^{-}\right)=-8.71$ (Table 2), one derives $\Delta G^{\text {water }}=1.60 \mathrm{kcal} / \mathrm{mol}$ or $K_{\mathrm{f}}^{\text {water }}=6.7 \times 10^{-2} \mathrm{l} / \mathrm{mol}$. These values show that, in water, the tetrachlorocobaltate(II) ion is indeed less stable than in DMF, DMA, DMSO or HMPA, in agreement with the results of semi-quantitative measurements ${ }^{69} \uparrow$. It should be noted that exactly the reverse behaviour would be expected according to the Born equation!

The foregoing considerations have been successfully applied also to the iodine-triiodide ion equilibrium ${ }^{67}$. Formation constants for equilibrium (40) are listed in Table 9.

$$
\mathrm{I}_{2}+\mathrm{I}^{-} \rightleftharpoons \mathrm{I}_{3}^{-}
$$

Table 9. Formation constants for equilibrium 40 in various non-aqueous solvents at $25^{\circ} \mathrm{C}^{72}$

\begin{tabular}{lrc}
\hline Solvent & $D N$ & $\log K_{\mathrm{f}}$ \\
\hline NM & 2.7 & 7.2 \\
AN & 14.1 & 6.8 \\
TMS & 14.8 & 7.5 \\
DMF & 26.6 & 7.1 \\
DMA & 27.8 & 7.4 \\
\hline
\end{tabular}

It is realized that the formation constants in solution are very similar although the donor properties of the solvents are widely different. Applying the same procedure as for the trichloro-tetrachlorocobaltate(II) equilibrium, the following equation is obtained ${ }^{67}$ :

$$
\Delta \Delta G_{(\mathrm{g})}=0.13 \times \Delta D N=\Delta \Delta G+0.92 \times \Delta \Delta G_{\mathrm{sv}}\left(\mathrm{I}^{-}\right)+0.40 \times \Delta \Delta G_{\mathrm{vp}}
$$

The results are graphically represented in Figure 12. Again a linear relationship is observed. As expected, the equilibrium constants in the gas phase decrease with increasing donicity. The slope of the line, $f=0.132$, is in excellent agreement with the value $f=0.147$ obtained independently from Figure 1. The value indicates that iodine is a very weak acceptor as compared

* In the case of benzonitrile, $\Delta \Delta G_{(\mathrm{g})}$ could not be determined, because $\Delta \Delta G_{\mathrm{sv}}\left(\mathrm{Cl}^{-}\right)$is not available for this solvent.

$\dagger K_{\mathrm{f}}^{\text {DMO }} \approx 2.71 / \mathrm{mol} ; K_{\mathrm{f}}^{\text {HMPA }} \approx 1.31 / \mathrm{mol}^{70,71}$. 


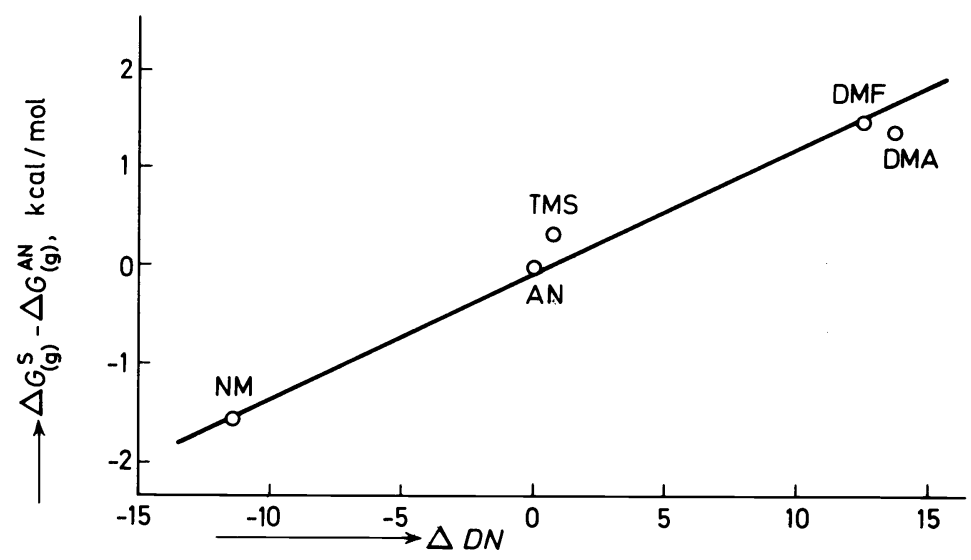

Figure 12. Free energies of formation of $\mathrm{I}_{3}^{-}$from $\mathrm{I}_{2} . \mathrm{S}$ and $\mathrm{I}^{-}$in the gas phase as a function of $D N$

with $\mathrm{SbCl}_{5}$. The value $b=0.4$ is close to the value $b=0.5$ obtained for the $\mathrm{CoCl}_{3}^{-}-\mathrm{CoCl}_{4}^{2-}$ equilibrium. The value $a=0.92$ indicates that the specific solvation energy contribution for the triiodide ion is much smaller than that of the iodide ion. This appears reasonable in view of the high degree of charge dispersion expected for the symmetrical triiodide ion.

Recently it has been shown that the model just outlined may be successfully applied also to the quantitative treatment of kinetic data ${ }^{67}$. Again, the trichloro-tetrachlorocobaltate(II) equilibrium has been used as model system. Rate constants for the forward and backward reaction of equilibrium (42) are listed in Table 10:

$$
\left[\mathrm{CoCl}_{3} \cdot \mathrm{S}\right]^{-}+\mathrm{Cl}^{-} \underset{k_{21}}{\stackrel{k_{12}}{\rightleftharpoons}}\left[\mathrm{CoCl}_{4}\right]^{2-}+\mathrm{S}
$$

Table 10. Rate constants for reaction 42 in various non-aqueous solvents at $20^{\circ} \mathrm{C}$, extrapolated to zero ionic strength ${ }^{68}$

\begin{tabular}{lll}
\hline Solvent & $k_{12}\left(1 \mathrm{~mol}^{-1} \mathrm{~s}^{-1}\right)$ & \multicolumn{1}{c}{$k_{21}\left(\mathrm{~s}^{-1}\right)$} \\
\hline NM & $(1.4 \pm 0.3) \times 10^{5}$ & $2.2 \pm 0.8$ \\
BN & $(1.1 \pm 0.1) \times 10^{3}$ & $0.3 \pm 0.05$ \\
AN & $(6.9 \pm 0.8) \times 10^{2}$ & $0.9 \pm 0.2$ \\
Acetone & $(7.9 \pm 1.0) \times 10^{2}$ & $0.3 \pm 0.05$ \\
DMF & $14.6 \pm 1.5$ & $0.9 \pm 0.2$ \\
DMA & $5.5 \pm 0.5$ & $0.17 \pm 0.05$ \\
\hline
\end{tabular}

Coordination chemical considerations as well as kinetic investigations strongly suggest that both reactions proceed by an SN2 mechanism with formation of a pentacoordinate transition state anion (43):

$$
\left[\mathrm{CoCl}_{4} \cdot \mathrm{S}\right]^{2-}
$$

In acetonitrile, for example, the entropy of activation of the forward reaction is $\Delta S^{\neq}=-30 \mathrm{cal} \mathrm{deg}^{-1} \mathrm{~mol}^{-1}$. This value closely corresponds to the 
entropy change calculated from the loss of translational degrees of freedom, associated with the formation of the activated complex. The same value was found for the backward reaction. Apart from the kinetic results, there are many examples of stable pentacoordinate $\mathrm{Co}$ (II) complexes. This suggests that the activation energy will be considerably lower for a pentacoordinate transition state than in the case of a dissociative mechanism.

According to Eyring's theory of the activated complex, an equilibrium exists between the activated complex and the reactants, which may be described by thermodynamic methods. This is illustrated by the thermochemical cycle (44), which applies to the forward reaction.

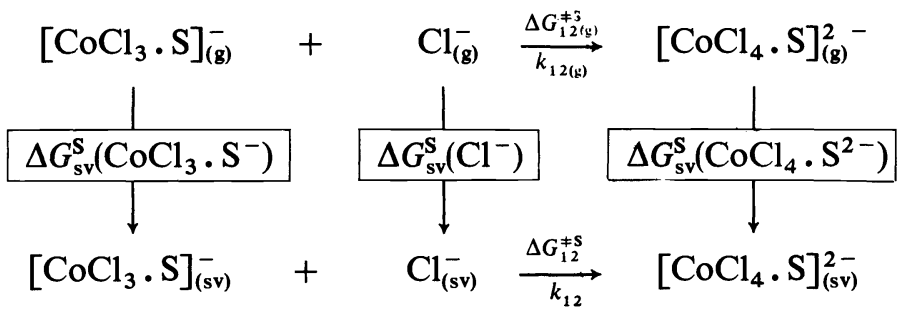

The following relationship is obtained for the free energies of activation in the gas phase and in solution:

$$
\Delta G_{12(\mathrm{~g})}^{\neq \mathrm{S}}=\Delta G_{12}^{\neq \mathrm{S}}+\Delta G_{\mathrm{sv}}^{\mathrm{S}}\left(\mathrm{Cl}^{-}\right)+\Delta G_{\mathrm{sv}}^{\mathrm{S}}\left(\mathrm{CoCl}_{3} \cdot \mathrm{S}^{-}\right)-\Delta G_{\mathrm{sv}}^{\mathrm{S}}\left(\mathrm{CoCl}_{4} \cdot \mathrm{S}^{2-}\right)
$$

The corresponding free energy differences for a solvent $\mathrm{S}$ and a reference solvent $R$ are given by:

$$
\begin{aligned}
\Delta \Delta G_{12(\mathrm{~g})}^{\neq}=\Delta \Delta G_{12}^{\neq}+\Delta \Delta G_{\mathrm{sv}}\left(\mathrm{Cl}^{-}\right)+\Delta \Delta G_{\mathrm{sv}} & \left(\mathrm{CoCl}_{3} \cdot \mathrm{S}^{-}\right) \\
& -\Delta \Delta G_{\mathrm{sv}}\left(\mathrm{CoCl}_{4} \cdot \mathrm{S}^{2-}\right)
\end{aligned}
$$

As with equation (35) the free energy of solvation of the transition state anion is related to the free energy of solvation of the chloride ion and the standard free energy of vaporization of the solvent:

$$
\Delta \Delta G_{\mathrm{sv}}\left(\mathrm{CoCl}_{4} \cdot \mathrm{S}^{2-}\right)=\alpha_{3} \times \Delta \Delta G_{\mathrm{sv}}\left(\mathrm{Cl}^{-}\right)-\beta_{3} \times \Delta \Delta G_{\mathrm{vp}}
$$

The term $-\beta_{3} \times \Delta \Delta G_{\mathrm{vp}}$ represents the free energy contribution originating from the interaction of the solvent molecule in the transition state anion with bulk solvent molecules. Substituting equations (35) and (47) into (46), one obtains :

$$
\Delta \Delta G_{12(\mathrm{~g})}^{\neq}=\Delta \Delta G_{12}^{\neq}+\left(1+\alpha_{2}-\alpha_{3}\right) \times \Delta \Delta G_{\mathrm{sv}}\left(\mathrm{Cl}^{-}\right)+\left(\beta_{3}-\beta_{2}\right) \times \Delta \Delta G_{\mathrm{vp}}
$$

or

$$
\Delta \Delta G_{12(\mathrm{~g})}^{\neq}=\Delta \Delta G_{12}^{\neq}+a_{12} \times \Delta \Delta G_{\mathrm{sv}}\left(\mathrm{Cl}^{-}\right)+b_{12} \times \Delta \Delta G_{\mathrm{vp}}
$$

with

* In $\Delta \Delta G_{s v}\left(\mathrm{CoCl}_{4} \cdot \mathrm{S}^{2-}\right)$ the symbol $\mathrm{S}$ stands both for the solvent $\mathrm{S}$ and the reference solvent $\mathrm{R}$. 


$$
\begin{gathered}
\text { U. MAYER } \\
a_{12}=1+\alpha_{2}-\alpha_{3} \\
b_{12}=\beta_{3}-\beta_{2}
\end{gathered}
$$

The free energy change of the gas phase reaction (52) is related to the donicity of the solvent molecules:

$$
\begin{aligned}
& {\left[\mathrm{CoCl}_{3} \cdot \mathrm{S}\right]_{(\mathrm{g})}^{-}+\mathrm{Cl}_{(\mathrm{g})}^{-} \rightarrow\left[\mathrm{CoCl}_{4} \cdot \mathrm{S}\right]_{(\mathrm{g})}^{2-}, \Delta G_{12(\mathrm{~g})}^{\neq \mathrm{S}}} \\
& \Delta G_{12(\mathrm{~g})}^{\neq \mathrm{S}}=-\Delta H^{\prime}+\Delta H^{\prime \prime}+\Delta H^{\prime \prime \prime}-T \times \Delta S_{12(\mathrm{~g})}^{\neq \mathrm{S}}
\end{aligned}
$$

The terms $\Delta H^{\prime}$ and $\Delta H^{\prime \prime}$ have the same meaning as previously. The enthalpy change $\Delta H^{\prime \prime \prime}$ refers to reaction (54) and is expected to be proportional to the donicity of $\mathrm{S}$.

$$
\begin{gathered}
{\left[\mathrm{CoCl}_{4}\right]_{(\mathrm{g})}^{2-}+S_{(\mathrm{g})} \rightarrow\left[\mathrm{CoCl}_{4} \cdot \mathrm{S}\right]_{(\mathrm{g})}^{2-}, \Delta H^{\prime \prime \prime}} \\
\Delta H^{\prime \prime \prime}=-f^{\prime \prime \prime} \times D N
\end{gathered}
$$

The coefficient $f^{\prime \prime \prime}$ represents a measure of the acceptor strength of the gaseous $\mathrm{CoCl}_{4}^{2-}$ ion relative to $\mathrm{SbCl}_{5}$.

Substituting equations (13) and (55) into equation (53), one obtains:

$$
\Delta G_{12(\mathrm{~g})}^{\neq \mathrm{S}}=\left(f-f^{\prime \prime \prime}\right) \times D N+\Delta H^{\prime \prime}-T \times \Delta S_{12(\mathrm{~g})}^{\neq \mathrm{S}}
$$

For reasons previously mentioned, $\Delta S_{12(\mathrm{~g})}^{\neq \mathbf{S}}$ may be considered as approximately constant for different molecules $\mathbf{S}$. Hence, the free energy difference for a solvent $\mathrm{S}$ and a reference solvent $\mathrm{R}$ is given by:

$$
\Delta \Delta G_{12(\mathrm{~g})}^{\neq}=\left(f-f^{\prime \prime}\right) \times \Delta D N=f_{12} \times \Delta D N
$$

According to the Eyring theory, the free energy of activation is related to the rate constant $k$ by:

$$
\Delta G^{*}=-R T \ln h \times N \times k / R T
$$

( $h=$ Planck's constant, $N=$ Avogadro's number).

The differences in activation energies in the gas phase and in solution are therefore given by:

$$
\Delta \Delta G_{12}^{\neq}=-R T \ln k_{12}^{\mathrm{S}} / k_{12}^{\mathrm{R}}
$$

and

$$
\Delta \Delta G_{12(\mathrm{~g})}^{\neq}=-R T \ln k_{12(\mathrm{~g})}^{\mathrm{S}} / k_{12(\mathrm{~g})}^{\mathrm{R}}
$$

Substituting equations (57), (59) and (60) into equation (49), one finally obtains :

$$
\begin{aligned}
\Delta \Delta G_{12(\mathrm{~g})}^{\neq} & =R T \ln k_{12(\mathrm{~g})}^{\mathrm{R}} / k_{12(\mathrm{~g})}^{\mathrm{S}}=f_{12} \times \Delta D N \\
& =R T \ln k_{12}^{\mathrm{R}} / k_{12}^{\mathrm{S}}+a_{12} \times \Delta \Delta G_{\mathrm{sv}}\left(\mathrm{Cl}^{-}\right)+b_{12} \times \Delta \Delta G_{\mathrm{vp}}
\end{aligned}
$$

A similar relationship can be derived for the backward reaction by considering the thermochemical cycle (62). 
IONIC EQUILIBRIA IN DONOR SOLVENTS

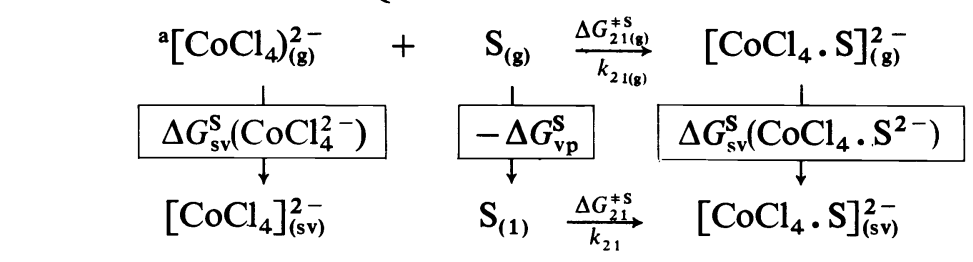

$\Delta \Delta G_{21(\mathrm{~g})}^{\neq}=\Delta \Delta G_{21}^{\neq}+\Delta \Delta G_{\mathrm{sv}}\left(\mathrm{CoCl}_{4}^{2-}\right)-\Delta \Delta G_{\mathrm{sv}}\left(\mathrm{CoCl}_{4} \cdot \mathrm{S}^{2-}\right)-\Delta \Delta G_{\mathrm{vp}}$

Using equations (34) and (47), one obtains :

$$
\Delta \Delta G_{21(\mathrm{~g})}^{\neq}=\Delta \Delta G_{21}^{\neq}+\left(\alpha_{1}-\alpha_{3}\right) \times \Delta \Delta G_{\mathrm{sv}}\left(\mathrm{Cl}^{-}\right)+\left(\beta_{3}-1\right) \times \Delta \Delta G_{\mathrm{vp}}
$$

or

$$
\Delta \Delta G_{21(\mathrm{~g})}^{\neq}=\Delta \Delta G_{21}^{\neq}+a_{21} \times \Delta \Delta G_{\mathrm{sv}}\left(\mathrm{Cl}^{-}\right)+b_{21} \times \Delta \Delta G_{\mathrm{vp}}
$$

with

$$
\begin{aligned}
& a_{21}=\alpha_{1}-\alpha_{3} \\
& b_{21}=\beta_{3}-1
\end{aligned}
$$

The free energy change of the gas phase reaction is again related to the donicity of the solvent :

$$
\Delta G_{21(\mathrm{~g})}^{\neq \mathrm{S}}=-f^{\prime \prime \prime} \times D N-T \cdot \Delta S_{21(\mathrm{~g})}^{\neq \mathrm{S}}
$$

and

$$
\Delta \Delta G_{21(\mathrm{~g})}^{*}=-f^{\prime \prime \prime} \times \Delta D N
$$

From equation (58) one further obtains :

$$
\Delta \Delta G_{21}^{\neq}=-R T \ln k_{21}^{\mathrm{S}} / k_{21}^{\mathrm{R}}
$$

and

$$
\Delta \Delta G_{21(\mathrm{~g})}^{\neq}=-R T \ln k_{21(\mathrm{~g})}^{\mathrm{S}} / k_{21(\mathrm{~g})}^{\mathrm{R}}
$$

Substituting equations (69) $-(71)$ into equation (65), one finally obtains :

$$
\begin{aligned}
-\Delta \Delta G_{21(\mathrm{~g})}^{\neq} & =R T \ln k_{21(\mathrm{~g})}^{\mathrm{S}} / k_{21(\mathrm{~g})}^{\mathrm{R}}=f^{\prime \prime \prime} \times \Delta D N \\
& =R T \ln k_{21}^{\mathrm{S}} / k_{21}^{\mathrm{R}}-a_{21} \times \Delta \Delta G_{\mathrm{sv}}\left(\mathrm{Cl}^{-}\right)-b_{21} \times \Delta \Delta G_{\mathrm{vp}}
\end{aligned}
$$

Experimentally the following equations have been obtained for the forward and backward reaction ${ }^{67}$ :

$$
\begin{array}{r}
\Delta \Delta G_{12(\mathrm{~g})}^{\neq}=0.25 \times \Delta D N=R T \ln k_{12}^{\mathrm{AN}} / k_{12}^{\mathrm{S}}+0.15 \times \Delta \Delta G_{\mathrm{sv}}\left(\mathrm{Cl}^{-}\right) \\
+0.00 \times \Delta \Delta G_{\mathrm{vp}} \\
\begin{aligned}
-\Delta \Delta G_{21(\mathrm{~g})}^{\neq}=0.09 \times \Delta D N=R T \ln k_{21}^{\mathrm{S}} / k_{21}^{\mathrm{AN}}+0.40 \times \Delta \Delta G_{\mathrm{sv}}\left(\mathrm{Cl}^{-}\right) \\
+0.60 \times \Delta \Delta G_{\mathrm{vp}}
\end{aligned}
\end{array}
$$

In equation (74) the coefficient $f^{\prime \prime \prime}=0.09$ represents a measure of the acceptor strength of the gaseous $\mathrm{CoCl}_{4}^{2-}$ ion relative to $\mathrm{SbCl}_{5}$. As expected,

* For formal reasons the symbol $f^{\prime \prime}$ should be replaced by the symbol $f_{21}$. 


\section{U. MAYER}

this ion is a still weaker acceptor than the $\mathrm{CoCl}_{3}^{-}$ion $(f=0.34)$. The coefficient $b_{21}=-0.6$ is numerically slightly larger than the value $b=0.5$ obtained for the equilibrium constants (equation 39). This is in agreement with structural considerations. The steric requirement of the $\mathrm{CoCl}_{4}^{2-}$ group (e.g. for a square pyramidal transition state) is somewhat larger than for the $\mathrm{CoCl}_{3}^{-}$group in the trichlorocobaltate(II) ion. Consequently, the interaction energy of the coordinated molecule with bulk solvent molecules will be smaller for the transition state anion than for the trichlorocobaltate(II) ion. This means that $\beta_{3}$ must be smaller than $\beta_{2}$. A small negative value should therefore be expected for the coefficient $b_{12}$ (equation 73), which equals the difference $\beta_{3}-\beta_{2}$. Experimentally, the value zero has been found. As previously stated, the $a$ coefficients are related to the charge distribution within the complex anions. Since the chloride ions are more strongly polarized in the transition state anion than in the tetrachlorocobaltate(II) ion, $\alpha_{3}$ is expected to be larger than $\alpha_{1}$. Consequently, $a_{12}$ must be smaller than $a$, in perfect agreement with the experimental findings. The coefficients of equations (36), (61) and (72) are related to each other through the basic equations (75) and (76):

$$
\begin{aligned}
& \Delta G_{(\mathrm{g})}^{\mathrm{S}}=\Delta G_{12(\mathrm{~g})}^{\neq \mathrm{S}}-\Delta G_{21(\mathrm{~g})}^{\neq \mathrm{S}} \\
& \Delta G^{\mathrm{S}}=\Delta G_{12}^{\neq \mathrm{S}}-\Delta G_{21}^{\neq \mathrm{S}}
\end{aligned}
$$

By matching of coefficients the following relationships are obtained:

$$
\begin{aligned}
& f=f_{12}+f^{\prime \prime \prime}=f_{12}+f_{21} \\
& a=a_{12}-a_{21} \\
& b=b_{12}-b_{21}
\end{aligned}
$$

The data in Table 11 show that equations (77)-(79) are indeed satisfied within the limits of experimental error.

Table 11. Experimental coefficients $a, b$ and $f$ of equations (36), (61) and (72)

\begin{tabular}{ccccccccc}
\hline$f$ & $f_{12}$ & $f_{21}=f^{\prime \prime \prime}$ & $a$ & $a_{12}$ & $a_{21}$ & $b$ & $b_{12}$ & $b_{21}$ \\
\hline 0.34 & 0.25 & 0.09 & 0.53 & 0.15 & -0.40 & 0.50 & 0.00 & -0.60 \\
\hline
\end{tabular}

Equation (74) shows that the experimental rate constants of the backward reaction are strongly influenced by the term $\Delta \Delta G_{\mathrm{sv}}\left(\mathrm{Cl}^{-}\right)$, although the chloride ion does not actually participate in this reaction. According to the present model, this is a consequence of different polarizations of the chloride ions in the transition state anion and the tetrachlorocobaltate(II) ion. Figure 13 shows that no relationship exists between the experimental rate constants of the backward reaction and the donicity of the solvents. In contrast, a linear correlation is obtained, if the rate constants of the gas phase reaction are plotted against $\triangle D N$ (Figure 14). As expected, the rate constants increase with increasing donor strength of the solvent molecules.

\footnotetext{
* See footnote to equation (72).
} 
IONIC EQUILIBRIA IN DONOR SOLVENTS

A linear relationship also exists between $\triangle D N$ and the gas phase rate constants of the forward reaction (Figure 15). Since the acceptor properties of the $\left[\mathrm{CoCl}_{3} . \mathrm{S}\right]^{-}$ion are weakened with increasing donor strength of the solvent molecules $\mathrm{S}$, the rate constants decrease with increasing donicity. The fact that the observed linear relationship covers a wide range of experimental rate constants (nearly five powers of ten!) strongly supports the previous assumption that the reaction proceeds by an SN2 mechanism. Equations

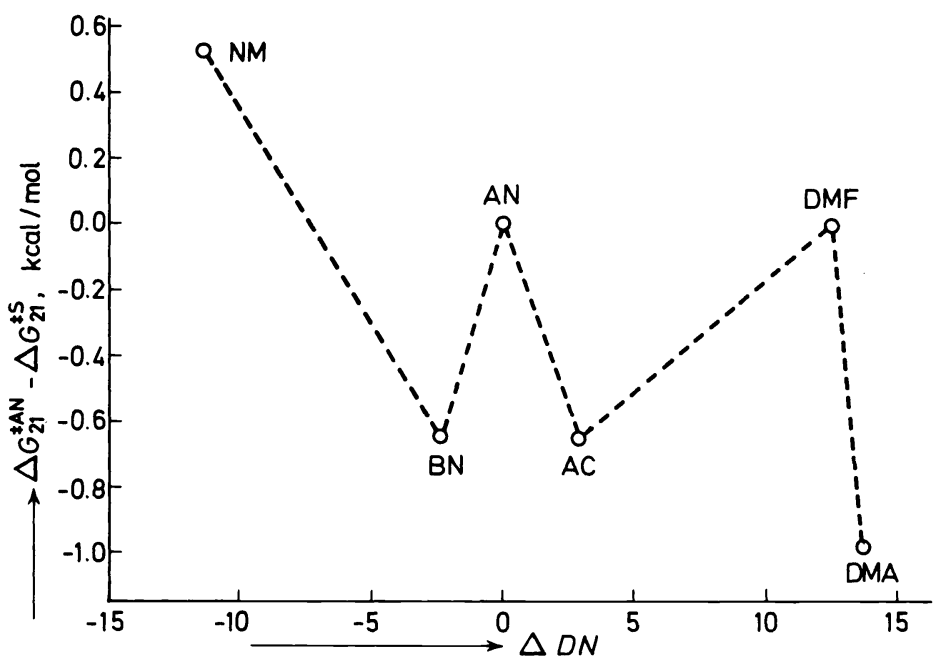

Figure 13. Experimental free energies of activation for the solvolysis of $\left[\mathrm{CoCl}_{4}\right]^{2-}$ to $\left[\mathrm{CoCl}_{3} . \mathrm{S}\right]^{-}$and $\mathrm{Cl}^{-}$in various donor solvents as a function of $D N$

(73) and (74) can be used to calculate rate constants for other solvents, provided that the quantities $\Delta D N, \Delta \Delta G_{\mathrm{sv}}\left(\mathrm{Cl}^{-}\right)$and $\Delta \Delta G_{\mathrm{vp}}$ are known.

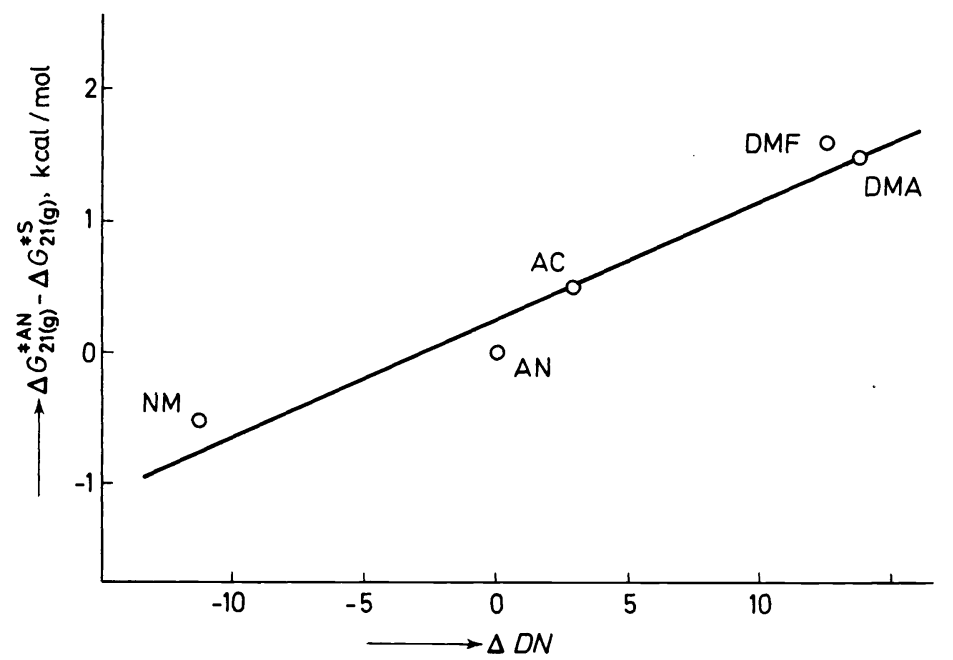

Figure 14. Free energies of activation for the formation of $\left[\mathrm{CoCl}_{3} . \mathrm{S}\right]^{-}$from $\left[\mathrm{CoCl}_{4}\right]^{2-}$ and $\mathrm{S}$ in the gas phase as a function of $D N$ 


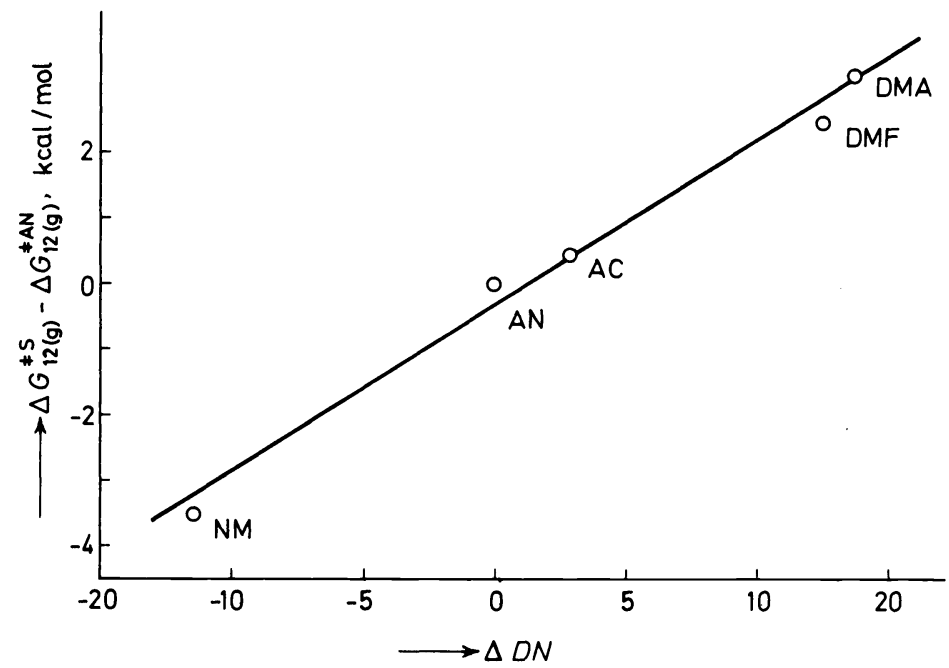

Figure 15. Free energies of activation for the formation of $\left[\mathrm{CoCl}_{4}\right]^{2-}$ from $\left[\mathrm{CoCl}_{3} \cdot \mathrm{S}\right]^{-}$and $\mathrm{Cl}^{-}$in the gas phase as a function of $D N$

Finally, it should be pointed out that the quantitative treatment of equilibria and reaction rates also offers the possibility to determine, by means of the coefficients $f$, relative acceptor strengths of acceptor groups or molecules. This is important in those cases where acceptor strengths cannot be directly determined.

\section{SUMMARY}

Elementary electrostatic models alone are usually inadequate for the description of ion-solvent interactions. The energy change associated with the solvation of ions can be represented as the sum of two energy terms. The main energy contribution arises from the dielectric polarization of the solvent molecules in the continuous dielectric medium. This energy contribution is large, but usually only small differences are observed for different solvents. This quantity may be estimated on the basis of continuous electrostatic models. The other energy term is due to specific ion-solvent interactions in the inner solvation shells of the ions. This energy contribution is much smaller but may show comparatively large differences in different solvents. It is therefore mainly responsible for specific differences in the solvating power of the solvents. As far as solvation of Lewis acids in donor solvents is concerned, the specific solvation energy term can be described by means of the donicity concept. The solvation of anionic species can be described by means of extrathermodynamic models. Both models allow a qualitative and, in part, even quantitative description of fundamental chemical equilibria and reaction rates in a variety of non-aqueous solvent systems. 
1 H. M. Koepp, H. Wendt and H. Strehlow. Z. Elektrochem. 64, 483 (1960).

2 O. Duschek and V. Gutmann, Monatsh. Chem. 104, 990 (1973).

3 E. Grunwald, G. Baughman and G. Kohnstam, J. Amer. Chem. Soc. 82, 5801 (1960).

${ }^{4}$ R. Alexander, E. C. F. Ko, A. J. Parker and T. J. Broxton, J. Amer. Chem. Soc. 90,5049 (1968).

5 R. Alexander, A. J. Parker, J. H. Sharp and W. E. Waghorne, J. Amer. Chem. Soc. 94, 1148 (1972).

6 V. Gutmann, Chemische Funktionslehre. Springer: Vienna (1971).

7 V. Gutmann, Structure and Bonding, 15, 141 (1973).

${ }^{8}$ I. Lindqvist, Inorganic Adduct Molecules of Oxo-Compounds. Springer: Berlin (1963).

9 V. Gutmann and E. Wychera, Inorg. Nucl. Chem. Letters, 2, 257 (1966).

10 V. Gutmann, Coordination Chenistry in Non Aqueous Solutions. Springer : Vienna (1968).

11 R. Paetzold, in MTP International Review of Science, Inorganic Chemistry Series Two. Vol. 3 (Ed. V. Gutmann). Butterworths : London (1974).

12 P. Spaziante and V. Gutmann, Inorg. Chim. Acta, 5, 273 (1971).

13 V. Gutmann, Topics in Current Chem. 27, 59 (1972).

14 U. Mayer and V. Gutmann, Structure and Bonding, 12, 113 (1972).

15 J. F. Coetzee, D. K. McGuire and J. L. Hedrick, J. Phys. Chem. 67, 1814 (1963).

16 O. Duschek and V. Gutman, Z. Anorg. Allg. Chem. 394, 243 (1972).

17 V. Gutmann, K. Danksagmüller and O. Duschek, Z. Phys. Chem. (Frankfurt), 92, 199 (1974).

18 U. Mayer and V. Gutmann, Advanc. Inorg. Chem. Radiochem., 17, 189 (1975).

19 U. Mayer and V. Gutmann, Monatsh. Chem. 101, 912 (1970).

20 M. Born, Z. Phys. 1, 45 (1920).

21 N. Bjerrum and E. Larsson, Z. Phys. Chem. 127, 358 (1927).

22 V. Gutmann and U. Mayer, Monatsh. Chem. 100, 2048 (1969).

${ }^{23}$ U. Mayer and V. Gutmann, Monatsh. Chem. 102, 148 (1971).

24 U. Mayer and V. Gutmann, Monatsh. Chem. 101, 997 (1970).

25 R. S. Drago, Lecture given at the Department of Inorganic Chemistry of the Technical University of Vienna, May 1974.

26 V. Gutmann, U. Mayer and P. Weihs, Monatsh. Chem., to be published.

27 H. J. Campell-Ferguson and E. A. V. Ebsworth, J. Chem. Soc. A, 705 (1967).

28 J. Y. Corey and R. West, J. Amer. Chem. Soc. 85, 4034 (1963).

29 I. R. Beattie and F. W. Parrett, J. Chem. Soc. A., 1784 (1966).

30 J. J. Brooks, W. Rhine and G. D. Stucky, J. Amer. Chem. Soc. 94, 7339 (1972).

31 T. E. Hogan-Esch and J. Smid, J. Amer. Chem. Soc. 88, 307 (1966).

32 T. E. Hogen-Esch and J. Smid, J. Amer. Chem. Soc. 88, 318 (1966).

${ }^{33}$ U. Mayer, V. Gutmann and A. Lodzinska, Monatsh. Chem. 104, 1045 (1973).

34 V. Gutmann and U. Mayer, Monatsh. Chem. 99, 1383 (1968).

35 M. K. Wong, W. J. McKinney and A. I. Popov, J. Phys. Chem. 75, 56 (1971).

36 W. F. Edgell, A. T. Lyford and W. Risen, J. Amer. Chem. Soc. 88, 1815 (1966).

37 W. F. Edgell, A. T. Lyford, R. Wright, W. Risen and A. Watts, J. Amer. Chem. Soc. 92,2240 (1970).

38 B. W. Maxey and A. I. Popov, J. Amer. Chem. Soc. 89, 2230 (1967).

39 B. W. Maxey and A. I. Popov, J. Amer. Chem. Soc. 91, 20 (1969).

40 J. L. Wuepper and A. I. Popov, J. Amer. Chem. Soc. 91, 4352 (1969).

41 J. L. Wuepper and A. I. Popov, J. Amer. Chem. Soc. 92, 1493 (1970).

42 W. J. McKinney and A. I. Popov, J. Phys. Chem. 74, 535 (1970).

43 V. Gutmann and R. Schmid. Coord. Chem. Rev. 12. 263 (1974).

44 V. Gutmann, Coord. Chem. Rev. 15, 207 (1975).

45 A. Werner, Liebigs Ann. 386, 1 (1912).

46 H. Taube and F. A. Posey, J. Amer. Chem. Soc. 75, 1463 (1953).

47 F. Basolo, P. M. Henry and R. G. Pearson, J. Amer. Chem. Soc. 79, 5379, 5382 (1957).

48 A. W. Adamson, J. Amer. Chem. Soc. 80, 3183 (1958).

49 T. C. Matts and P. Moore, J. Chem. Soc. 219 (1969).

50 P. J. Staples, J. Chem. Soc. 2731 (1968).

51 W. G. Movius and R. G. Linck, J. Amer. Chem. Soc. 92, 2677 (1970).

52 V. Gutmann, K. Danksagmüller and G. Gritzner, to be published.

53 W. R. Fitzgerald and D. W. Watts, J. Amer. Chem. Soc. 89, 821 (1967). 


\section{U. MAYER}

54 W. A. Millen and D. W. Watts, J. Amer. Chem. Soc. 89, 6858 (1967).

55 U. Mayer, V. Gutmann and W. Gerger, to be published.

56 V. Gutmann and U. Mayer, Rev. Chim. Minérale, 8, 429 (1971).

57 F. Dickert, H. Hoffmann and W. Jaenicke, Ber. Bunsenges. Phys. Chem. 74, 500 (1970).

58 F. Dickert and H. Hoffmann, Ber. Bunsenges. Phys. Chem. 75, 1320 (1971).

59 H. Hoffmann, T. Janjic and R. Sperati, Ber. Bunsenges. Phys Chem. 78, 223 (1974).

60 M. Eigen and R. G. Wilkins, in Mechanisms of Inorganic Reactions, Advanc. Chem. Ser. No. 49 (Ed. R. F. Gould). American Chemical Society: Washington, DC (1965).

61 V. Gutmann and R. Schmid, Monatsh. Chem. 102, 1217 (1971).

62 W. R. Fitzgerald, A. J. Parker and D. W. Watts, J. Amer. Chem. Soc. 90,5744 (1968).

${ }^{63}$ F. Basolo and R. G. Pearson, Mechanisms of Inorganic Reactions. 2nd ed. Wiley: New York (1967).

64 C. H. Langford and V. S. Sastri, in MTP International Review of Science, Inorganic Chemistry Series One. Vol. 9. (Ed. M. L. Tobe), Butterworths: London (1972).

65 C. H. Langford and W. R. Muir, J. Amer. Chem. Soc. 89, 3141 (1967).

66 This work.

67 U. Mayer, Monatsh. Chem., 106 (1975).

${ }^{68}$ W. Tschebull, V. Gutmann and U. Mayer, Z. Anorg. Allg. Chem., to be published

${ }^{69}$ U. Mayer and V. Gutmann, unpublished.

70 K. R. Magnell and W. L. Reynolds, Inorg. Chim. Acta 6, 571 (1972).

71 V. Gutmann and A. Weisz, Monatsh. Chem. 100, 2104 (1969).

72 A. J. Parker and R. Alexander, J. Amer. Chem. Soc. 90, 3313 (1968). 